2. LOS FUNDAMENTOS SOCIO-POLÍTICOS DE LA JURISDICCIÓN CONSTITUCIONAL

\author{
JUAN GARCIA COTARELO \\ Profesor Titular de Derecho Constitucional \\ Universidad de Alcalá de Henares
}




\section{SUMARIO}

Introducción.-I. Estados Unidos.-II. Gran Bretaña.-III. AleMANIA. 
Revista de Derecho Político, núm. 33, 1991, pp. 27-75

\title{
2. LOS FUNDAMENTOS SOCIO-POLÍTICOS DE LA JURISDICCIÓN CONSTITUCIONAL
}

\author{
POR \\ JUAN GARCIA COTARELO \\ Profesor Titular de Derecho Constitucional \\ Universidad de Alcalá de Henares
}

INTRODUCCIÓN

El surgimiento de los Estados modernos, paralelamente a la aparición de Constituciones escritas, supone para la clase politica que lleva a cabo la transformación, afrontar una contradicción entre el orden económico, el político y el jurídico no planteada hasta entonces. La solución requirió la creación de instituciones (esencialmente la jurisdicción constitucional), cuyo sentido se encuentra ampliamente determinado por la nueva relación entre factores sociales, politicos y económicos con que se define el constitucionalismo clásico, entendiendo por tal aquel que cubre el siglo XIX hasta el período de entreguerras.

En el marco de una perspectiva globalizadora, que entiende la evolución de los sistemas como dinámica de las entidades complejas en las que los problemas movilizan sus propios soluciones ', puede observarse cómo la jurisdicción constitucional nace con una clara vocación conservadora. Nace para ejercer aquellas funciones inherentes al propio concepto de derecho, cuales son la estabilidad y previsibilidad de las relaciones sociales. Estas funciones son las que cumplirá el derecho en los sistemas políticos modernos $y$, con carácter eminente, esto es, entre los propios órganos de dicho sistema, corresponderá a la jurisdicción constitucional.

- Sobre la cuestión de la autorregulación de los sistemas sociales a través de la diferenciación interna, como mecanismo reductor de complejidad, ver N. LuHMANN, "Reflexive Mechanismen» (1966), "Soziologie als Theorie soziales Systeme" (1967), en Soziologische Aufklärung, 4, ed. 1974. 
El recurso al derecho se hace más necesario cuanto más evidente es el desorden y la incertidumbre relacional (litigios), y el recurso al derecho político -que en grado eminente incorpora la jurisdicción constitucional- se impone más perentoriamente cuanto más intensa es la hybris política. Ello ocurre en las revoluciones y, más precisamente, en las révoluciones democráticas. La jurisdicción constitucional - según la tesis del presente trabajo- surge, históricamente hablando, como reacción cautelar conservadora ante la eventual desmesura en las actuaciones de un legislador democráticamente legitimado.

El problema central de la constitucionalización del Estado a finales del siglo XVIII es el planteado por la capacidad dispositiva del órgano característico del constitucionalismo moderno: el órgano representativo. La noción de mandato representativo, elaborada por la doctrina constitucional inglesa (Burke), es adoptada por todos los paises que acceden al orden constitucional moderno como forma de articular la relación entre el colectivo de electores y el elegido. En este sentido el representante político, a diferencia del representante o apoderado de derecho privado, actúa por voluntad propia, pero en interés de otro (Biscaretti). La libertad que ello confiere al representante hace de la institución en la que se integra (Congreso, Asamblea, Parlamento...) un órgano no controlable de actuación. Aquí reside, precisamente, el núcleo del problema, en la posible discrecionalidad reguladora de un órgano de decisión potencialmente libre y, con ello, la amenaza que, desde un órgano Legislativo de esta naturaleza, se cierne sobre el código de valores de la burguesía: «life, liberty and property" (Locke).

Las soluciones que el sistema social (entendido el término en el sentido de Parsons, como sistema omnicomprensivo en el que se incluye tanto la colectividad como el orden jurídico-político de que se dota) moviliza frente a dicho problema son esencialmente dos, una vez que, como demuestra el decurso de la Revolución Francesa, la mera aplicación del principio de separación de poderes no garantiza la intangibilidad de aquel código de valores ${ }^{2}$. Los dos instrumentos con que se cuenta para ejercer la limitación efectiva del órgano Legislativo son: el censitarismo electoral y la revisión judicial de la constitucionalidad de las leyes. Cuales sean los sistemas sociales que opten por una u otra de las soluciones, dependerá de la incorporación o no a los mismos del principio democrático. Aquellos sistemas en los que impere una democracia representativa, se recurrirá obviamente al instrumento de control judicial de la función legislativa. Esta conexión puede apreciarse en la organización constitucional de tres de los

2 De qué sirve que el Ejecutivo no pueda oprimir por propia iniciativa si existe la posibilidad de que se pueda acoger a leyes injustas para poder hacerlo «legalmente». 
Estados modernos más representativos: Estados Unidos, Inglaterra y Alemania.

\section{ESTADOS UNIDOS}

La vinculación estructural entre representatividad democrática y revisión judicial o limitación judicial del Legislativo se establece con toda claridad en el proceso constituyente americano. Siguiendo esta orientación la investigación estadounidense ha efectuado un replanteamiento del significado de El Federalista, afirmando que se había aceptado erróneamente "that it was necessary to convince the antifederalists of the need for a stronger federal union, when what was needed was to convince them that the stronger union proposed by the Philadelphia Convention would not endanger personal liberty» ${ }^{3}$.

Los recelos frente a la ilimitación del poder Legislativo democráticamente legitimado, surgen como producto de la experiencia habida durante los años que median entre la independencia de las colonias norteamericanas de Inglaterra y la convocatoria de la Convención de Philadelphia, que redactaria la Constitución federal de los Estados Unidos ${ }^{4}$. La ilimitación con que el entusiasmo democrático había configurado las legislaturas en las Constituciones de los distintos Estados, fue la cuestión más unánimemente criticada por los miembros de la Asamblea Constituyente. De hecho, puede afirmarse que la propia convocatoria de la Convención fue producto precisamente de los excesos a los que la ilimitación de poder condujo a las legislaturas estatales ${ }^{5}$. Los excesos e injusticias cometidos por éstas durante los diez años que, más o menos, dependiendo de los distintos

\section{pág. 8.}

3 Cit. en Raul Berger, Congres v. The Supreme Court, Massachusetts 1969,

4 Jefferson dirá refiriéndose a la Constitución de Virginia en 1781 que «was formed when we were new and unexperimented in the science of government... No wonder then that time and trial have discovered very capitals defects in its (v. R. BERGER, op. cit, pág. 10).

5 Madison dirá en la Convención que la interferencia con la "security of private rights and the steady dispensation of Justice (...) were evils which had more perhaps than anything else produced this convention" (Max Farrand, edt.), The Records of the Federal Convention. vol. I, New Haven, 1911, pág. 134) y James Wilson afirmará que «we have seen the Legislatures in our own country deprive the citizen of Life, of Liberty and Property, we have seen Attainders, Banishement \& Confiscations» (M. FARRAND, op. cit., vol. ll, pág. 76). 
Estados ${ }^{6}$, duran las legislaturas estatales, fueron sólo la lógica consecuencia de la filosofía política que los inspiró ${ }^{7}$. Las Convenciones en que se aprobaron las primeras Constituciones estatales eran órganos revolucionarios y, como tales, desconocedores de la diferencia entre poder constituyente -en tanto que manifestación suprema y ocasional de la soberanía- y poderes constituidos -entendidos como ejercicio limitado del poder soberano-. Debido a ello las Constituciones escritas de los Estados no difieren en rango de las leyes ordinarias. En sí misma, la idea de Constitución entendida como norma de rango ordinario, resulta coherente con el individualismo radical del pensamiento democrático americano de este período. De este modo, para Jefferson no sólo la Constitución no se sitúa por encima del Legislativo, sino que todo derecho escrito estaba sometido a derogación automática al cabo de un tiempo prefijado. Las decisiones referentes al orden formalizado de la colectividad (Constitución, Códigos, ordenamiento general...) válidas para la generación que las había tomado, no deberian vincular a las siguientes ${ }^{8}$. El principio de libertad individual encuentra en la idea jeffersoniana de autodeterminación generacional frente a todo orden formalizado existente, su máxima expresión colectiva.

Inspirados en esta filosofía política, los procesos constituyentes de los Estados americanos en los primeros tiempos de la independencia optaron por la prevalencia del órgano (Asamblea constituyente) frente al resultado (Constitución escrita). La Constitución de Pennsylvania - redactada en gran parte por B. Franklin- preveía que, como máximo, cada siete años el Consejo de Censores ${ }^{9}$ examinase la eventual elaboración de una nueva Constitución. La Constitución de Massachusetts incluía una cláusula que garantizaba la convocatoria de una nueva Convención constituyente al cabo de cinco años ${ }^{10}$. En el primer constitucionalismo norteamericano la Constitución era, bien un instrumento de rango ordinario $\mathrm{y}$, por tanto, subordinado al poder Legislativo, bien de duración limitada y, consiguientemente, de validez igualmente condicionada al órgano Legislativo. Ello es consecuencia de la preeminencia que adquieren las Asambleas legislativas en

- Las cuatro primeras Constituciones (Virginia, Pennsylvania, New Hampshire y South Carolina) fueron aprobadas en 1776, y la última, la de Massachusetts, lo fue en 1780 .

7 Filosofía que encontraba la atmósfera adecuada en el periodo de transición entre la desaparición de la autoridad británica sobre las colonias americanas y la instauración de un orden político propio. Era una situación en la que, como recoge Channing, "the people in each colony loked upon themselves either as being in a "state of nature" or as forming "society"» (Edward Channing, A History of the United States. New York, vol. III, pág. 431).

${ }^{8}$ E. Channing, op. cit., III, pág. 445.

9 Cuyo cometido era velar por la integridad de la Constitución, aunque no podia anular las leyes aprobadas por el Legislativo (E. Channing, op. cit., III, página 439.

to E. Channing, op. cit., III, pág. 441. 
períodos revolucionarios ${ }^{*}$. Preeminencia que también quedaba reflejada en la fusión de poderes que caracterizaban a las formas de Gobierno. Los órganos Ejecutivos disponian de plazos muy breves (la Constitución de Virginia establece el mandato del Gobernador en un año y elegido por las Cámaras) y eran extremadamente débiles (en la Constitución de Pennsylvania el Ejecutivo era colectivo y no podia oponerse a las decisiones de la legislatura, que era monocarameral y, por tanto, muy fuerte). Existía, en consecuencia, una preeminencia orgánica de las Cámaras legislativas respecto del resto de los órganos del Estado. Resulta lógica la reflexión que hará JEFFERSON en 1871 refiriéndose a la Constitución de Virginia: " All the powers of government, legislative, executive and judiciary result to the legislative body. The concentrating these in the same hands is precisely the definition of despotic government. (...) An elective despotims was not the government we fought for" ${ }^{12}$.

En la Convención de Philadelphia, de donde salió el texto constitucional de los Estados Unidos, el punto en el que coincidian todos sus integrantes era la necesidad de establecer formas de limitación de los órganos Legislativos. Para WILSON, unos de los miembros de la Convención, "If the Legis/ative authority be not restrained, thera can be neither liberty nor stability» ${ }^{13}$. El poder Legislativo debería ser un poder limitado, ya que, como dira Wilson, "for of all kinds of despotism, this is the most dreadful and the most difficult to be corrected" ${ }^{14}$. Se puede entonces afirmar que una de las más generalizadas convicciones en la Convención de 1787 era que "the greatest danger to liberty arises from the expanding power of the legislative bodys ${ }^{15}$.

La desconfianza de los constituyentes respecto del poder Legislativo se fundaba no en la experiencia de las colonias con el Parlamento de Inglaterra sino en las experiencias tenidas por los ciudadanos de los trece primeros Estados con los órganos Legislativos de que ellos se habian dotado.

Si pensamos que la legislatura a la que los constituyentes de Philadelphia querían saber limitada era siempre un órgano democráticamente

11 Asambleas que derivaban su composición del ejercicio del sufragio universal masculino, reconocido en todas las Constituciones estatales. La Constitución de Virginia concedía el derecho de sufragio a todos los habitantes del Estado con permanente interés y adhesión a la comunidad. La Constitución de Pennsylvania concedia el derecho de voto a todo varón de 21 años con un año de residencia en el Estado y que pagase algún impuesto (v. E. ChANNING, op. cit., III, pág. 430 y ss.

12 Cit. R. Berger, op. cit., pág. 10.

13 M. FaRRAND, op. cit., I, pág. 254.

14 Cit. en John B. McMaster/F. D. Stone, Pennsylvania and the federal Constitution 1787-1788, Lancaster, 1888, pág. 304.

${ }^{15}$ Cit. en Charles G. Haines, The Role of the Supreme Court in American Government and Politics, New York 1960, vol. I, pág. 208. 
legitimado, no ha de extrañar que el movimiento constituyente que dio origen a la Convención de Philadelphia esté animado por un espíritu restrictivo del ideario democrático que desencadenará e impulsará el movimiento revolucionario de la independencia americana. No resulta excesiva entonces la afirmación de BECK de que, salvo raras excepciones, los miembros de la Convención adoptasen una actitud escéptica y hasta contraria al sistema democrático ${ }^{16}$. Todo ello determinó las exigencias de la Convención para que los «Congressional powers» quedasen explícitamente vinculados, interponiendo suficientes protecciones contra futuras extralimitaciones. Temores a este respecto se expresaron con claridad en las Convenciones estatales para la ratificación de la Constitución federal. En todas ellas se mantiene y afirma la tesis de que el Congreso no tiene más poder que el expresamente atribuido por el texto constitucional, careciendo de autoridad para legislar más allá de los poderes enumerados ${ }^{17}$. Lo cual no pasa de ser una aplicación del principio ultra vires del Common Law - conocido evidentemente por los constituyentes-, por el que la actuación de un agente (apoderado) fuera del marco de la autoridad delegada no vincula a los delegantes. A ello alude HAMILTON en el «Ensayo 78» de El Federalista, cuando afirma que «every act of delegated authority, contrary to the tenor of the commission, under which it is exercised, is void. No legislative act, therefore, contrary to the Constitution, can be valid" ${ }^{18}$. El Congreso era presentado por los partidarios de la Consitución de 1787 como una legislatura de poderes delegados «indeed, of powers delegated piecemal»" ${ }^{19}$.

Los potenciales excesos de la legislatura a los que se pretendía neutralizar para siempre eran aquellos que afectaban esencialmente a los derechos privados de los indivudos que, en síntesis, podrían resumirse en la trilogía nuclear del liberalismo burgués: «personal liberty, private property and personal safety" ${ }^{20}$, según los términos en que los expresara Gouvernor MORRIS en la propia Convención. Enumeración en la que obviamente la cuestión de la propiedad privada y la riqueza constituye la parte más sensible a potenciales regulaciones que atenten contra el status quo de su distribución. De ello es testigo el propio MADISON, quien afirmará que la minoria de propietarios ha encontrado a menudo sus derechos «de-

16 James M. BECK, The Court of the United States, Yesterday, Today and Tomorrow, New York 1924, pág. 206.

17 «If Congress, under pretence of executing power, should, in fact usurp another, they will violate the Constitution» dirá Archibal McLaine en la Convención de North Carolina. O también James Iredell, en la misma Convención, dirá que una ley "not warranted by the Constitution is barefaced usurpation» (cit. en R. BERGER, op cit., pág. 14 y ss.).

${ }_{18}$ The Federalist, New York 1937, Ensayo 78, pág. 505.

19 Edward S. Corwin, Court over Constitution: A Study of Judicial Review as an Instrument of Popular Government, Princenton 1938, pág. 20.

20 M. Farrand, op. cit., I, pág. 512. 
cided, not according to the rules of justice... but by superior force of an interested and over-bearing majority" ${ }^{21}$. La necesaria complementación de la decisión mayoritaria, propia del ideario democrático, habrá de operarse a través del principio de las minorias. En otros términos, la exigencia de asegurar a la voluntad de la minoría frente a la opinión mayoritaria. Dotar de efectividad a los límites inherentes a las decisiones de la mayoría, configurando ámbitos indisponibles a su voluntad ${ }^{22}$.

Para el pensamiento político de la época la idea de los tribunales como garantes de las libertades frente a las legislaturas era una noción familiar, anclada en la tradición de la independencia judicial inglesa. Las declaraciones de los framers en las diversas Convenciones de ratificación de la Constitución federal, confirman la aceptación de esta tradicional facultad enraizada en los jueces. Para RANDOLPH, en la Convención de Virginia «If Congress wish to aggrandize themselves by oppressing the people, the judiciary must first be corrupted" ${ }^{23}$. Del mismo modo WILSON, en la Convención de Pennsylvania, mantendrá que «personal liberty and private property, depend essentially upon the able and upright determination of upright judges» ${ }^{24}$. Se aplicaba aquí la tradición inglesa de contemplar en los jueces y tribunales instituciones garantizadoras de las libertades individuales ${ }^{25} \mathrm{e}$, implícitamente, una contención de la soberanía del Parlamento en favor de los particulares ${ }^{26}$. Durante el siglo XVIII prevalecia en

${ }^{21}$ The Federalist, Ensayo 10, pág. 54.

22 Suele esgrimirse como argumento en contrario respecto de la trascendencia que los constituyentes otorgaban a los derechos fundamentales y, por tanto, a la protección de las minorias, la ausencia de una declaración de derechos (ver, por ejemplo, Louis B. Boudin, Government by Judiciary, New York 1936, pág. 116). Sin embargo, esta ausencia no menoscaba la de los derechos individuales como límites a la legislatura y, por ende, la de los jueces como garantes de estos límites. Por el contrario, los integrantes de las Convenciones de ratificación de la Constitución federal mantenian el criterio de que «in a government of limited and enumerated powers a bill of rights was superfluos, even dangerous, because rights which would no be enumerated would be threatened" (cit. en R. BERGER, op. cit., pág. 19). En realidad, el que los derechos fundamentales se recogiesen en una declaración específica fuera de la Constitución, para ser posteriormente incorporados a la misma, en ello se manifiesta precisamente el carácter supraestatal de estos derechos. No están entendidos como derechos concedidos por el Estado, sino como auténticos derechos naturales inherentes a la persona.

${ }^{23}$ Cit. en R. BERGER, op. cit., pág. 20.

24 Idem, pág. 20.

25 Como recoge HART, "Courts were fought of in part, of course, as instruments for the protection of individuals» (Henry M. HART/Herbert WECHSLER, The Federa/ Courts and the Federal System, Brooklyn 1950, pág. 11.

${ }_{26}$ Para el pensamiento constitucional americano de la época seguía viva la filosofía que inspirara el criterio del juez Coke en el Bonham's Case, como lo prueba la invocación de esta doctrina por James Otis en 1761, concluyendo que «it will not be considered a new doctrine that even the authority of the parliament of Great 
América la opinión de que la función de los jueces consistia en «to settle the contents between prerrogative and liberty (...) to ascertain the bounds of sovereign power, and to determine the rights of the subjects ${ }^{27}$. La cuestión que se plantea entonces es, que si los americanos rechazan ya desde la época colonial la supremacia del Parlamento, ¿cómo se explica la concentración de poderes con que invisten a los Legislativos en sus propios Estados al establecer sus propias Constituciones? Como opina R. BERGER, ello no quería suponer la recepción de la "omnipotencia legislativa», sino una radical repulsa a la propia experiencia colonial «local assemblies were trusted because they had been chosen by the Colonists themselves, not trust upon them by the King as were the governors and judges» ${ }^{28}$. Aunque no hay que descartar la influencia que sobre las Constituciones de los Estados tuvieron los idearios democrático-revolucionarios de aquellos sectores de la población colonial, que veían en los Legislativos todopoderosos de los Estados el instrumento para el desarrollo de reformas radicales de orden socioèconómico ${ }^{29}$.

La idea de la supremacia y omnipotencia del Parlamento, que se impone en el constitucionalismo inglés en el siglo XVIII ${ }^{30}$, no encuentra ninguna acogida en los Estados americanos. Entre éstos prevalece la concepción de VATTEL - cuya autoridad entre los norteamericanos era in-

Britain is circunscribed by certain bounds, which if exceeded, their acts become those of meer power without right, and consequently void. The judges of England have declared in favor of these sentiments ... that acts against the fundamental principles of the British Constitution are void» (cit. en R. BERGER, op. cit., pág. 25).

${ }_{27}$ Bernard BAILYN, The Ideological Origins of the American Revolution, Massachusetts 1967, pág. 74.

28 R. Berger, op. cit., pág. 30.

29 "The radicals set about not only to democratize political institutions but also to destroy the social, economic and religious privileges which had been inherited from Europa and which were fostered and strongly approved by the conservatives» (Ch. G. HAINES, op. cit., vol. I, pág. 56).

so "The omnipotence of Parliament was not the ortodox theory of English law, if ortodox at all, even in Holt's time. It was first formally adopted ... in Blackstone's Commentaries ... Down to the Revolution, the common legal opinicn was that statutes might be void as 'contrary to common right» (Sir Frederick PoLLOK, "A Plea for Historical Interpretation", Law Quartely Review 39, 1923, pág. 163. Por su parte, en la Convención de Pennsylvania WILSON expone con claridad la limitación del poder Legislativo por medio de la Constitución, rechazando la supremacia parlamentaria de Blackstone: «Sir William Blackstone will tell you in Britain ... the Parliament may alter the form of the government and that its power is absolute, without control... To control the power and conduct of the legis/ature, by an overruling constitution, was an improvement in the science and practice of government reserved to the American states", siendo el principal instrumento de este control la «interposition of the judicial department» (cit. en R. BERger, op. cit., pág. 34). 
discutida ${ }^{31}$. - para quien "l'autorité de ces législateurs ne va pas si loin et que les lois fondamentales doivent être sacrées pour eux (...) Enfin, c'est de la Constitution que ces législateurs tiennent leurs pouvoirs. Comment pourraient ils la changer sans détruire le fondement de leur autorité?" ${ }^{32}$. El entendimiento de la Constitución como una ley fundamental y fundamentadora era familiar al pensamiento norteamericano.

La idea whig de la soberanía del Parlamento, aunque enunciada de manera rotunda por BLACKSTONE ${ }^{33}$, experimenta en el propio autor fuertes limitaciones. El mismo Blackstone recoge que "the omnipotence of parliament» es «a figure rather too bold» ${ }^{34}$ y cuyo sentido era la evidencia de la subordinación del poder Judicial al Parlamento. No obstante, Blackstone admite límites inherentes a toda legislación, recogidos en la tradición de los derechos fundamentales de los hombres libres, esto es, los "absolute rights» de todo inglés, entre los que se incluyen la "personal security", la "personal liberty" y la "private property" ${ }^{35}$. Concluyendo que la ley "will no authorize the least violation of private propertys ${ }^{36}$. Evidentemente, Blackstone sostiene los mismos criterios que informaran la judicial review americana y que se fundamentan en un interés de conservación del status quo socio-económico. No obstante, y dentro del contexto histórico de los intereses dominantes de la burguesía, la soberanía del Parlamento inglés es un hecho inobjetable.

Por el contrario, en el proceso constituyente norteamericano confluyen todos aquellos factores conducentes a la supremacía de los jueces bajo la forma de la judicial review. Por un lado, la continuidad de la tradición inglesa, que contempla a los jueces como órganos independientes creadores del derecho, y el rechazo de la soberanía del Parlamento, que en los Estados americanos cede ante la idea de que la legislatura es un poder inherentemente limitado ${ }^{37}$. Todo ello se complementa, por otro, con la idea

${ }^{31}$ El tratado de VATTEL, Droit de Gens (1760) y su doctrina constitucional era algo comúnmente aceptado en las colonias americanas antes de la revolución (ver E. S. CorwIN, The Doctrine of Judicial Review: Its Legal and Historical Basis, Massachusetts, 1963, pág. 20), Su influencia se encuentra con toda claridad en S. Adams y J. Otis.

32 Vattel, Droit de Gens, lib. I, cap. III, § 34, citado por Esmein, Eléments de Droit Constitutionnel français et comparé», 7. ${ }^{a}$ ed., l, pág. 567, Paris 1921.

${ }_{33}$ W. Blacksdtone, Commentaries on the Laws of England. Garland Publishing, New York, London 1978, vol. I, pág. 91.

${ }^{34}$ Ibidem, I, pág. 161.

35 Ibidem, l, pág. 127 y ss.

36 Ibidem, l, pág. 139.

37 Como señala CoRWIN (The Doctrine of Judicial Review): «in one form or another, the notion of legislative power as inherently limited power, distinct from and exclusive of the power of interpreting the standing law, was reiterated again and again and was never contradicted" (The Doctrine of Judicial Review, cit., página 42). 
de que la Constitución era una fundamental law ante la que el resto de las leyes ha de doblegarse. Concepción que necesariamente admitía que la Constitución era, en sí misma, una ley y que es función propia de los jueces -y no de la legislatura- interpretar y aplicar las leyes. Asi lo expone el propio HAMILTON en el "Ensayo 78" de El Federalista: "The interpretation of the laws is the proper and peculiar province of the courts. A Constitution is in fact, and must be regarded by the judges, as a fundamental law. It therefore belongs to them to ascertain its meaning as well as the meaning of any particular act proceeding from legislative body" ${ }^{38}$.

Se puede afirmar que los constituyentes de Philadelphia eran conscientes de los problemas que planteaba, para la estabilidad de un orden político, la existencia de un órgano desmesurable. Igualmente eran conscientes que el único poder suceptible de impedir los excesos del Legislativo se encontraba en los jueces; el poder judicial federal era «the check on popular rule» ${ }^{39}$. Ellos son los encargados de dar efectividad a la fuerza normativa de la Constitución, como enuncia MADISON, "a law violating a treaty ratified by pre-existing law, might be respected by the judges as a law, though an unwise or perfidious one. A law violating a Constitution established by the people themselves, would be considered by the judges as null and void" ${ }^{40}$. En términos más técnicos, propios de Hamilton, encontramos la misma idea en El Federalista ${ }^{41}$ : «The Constitution ought to be the standard of construction of the laws, and ... wherever there is an evident opposition, the laws ought to give place to the Constitution" ${ }^{42}$.

Ambas instituciones - la supremacia jurídica de la Constitución y el poder de revisión judicial de las leyes- se complementan. Pero la judicial review no se entendía como una consecuencia de la lógica normativa aplicada a la cláusula de supremacía, sino como un instrumento con objetivos esencialmente políticos. La revisión judicial, dirá Hamilton en el célebre «Ensayo 78», supone «an excellent barrier to the encroachments and opressions of the representative body» ${ }^{43}$. Cierto que Hamilton incorporaba la orientación más conservadora y aristocrática de la Asamblea constituyente y que, por tanto, «A Constitution which effectively closed the avenues to change guarded by the federal Judiciary through the process of interpretation was one of the chief objectives in the program of Hamiltonian Federalis $m \gg{ }^{44}$. Pero prescindiendo de su repugnancia hacia un Gobierno po-

38 The Federalist, Ensayo 78, pág. 508.

39 J. Allen SNITH, The Spirit of American Government, New York 1907, página 105.

40 M. Farrand, op. cit., II, pág. 93.

41 Hay que tener en cuenta que fue HAMILTON quien asumió la redacción de los ensayos dedicados al poder judicial.

${ }_{42}$ The Federalist, Ensayo 81, pág. 524.

43 Ibidem, cit. Ensayo 78, pág. 503.

44 Ch. G. HaINES, op. cit., I, pág. 199. 
pular, Hamilton coincidia con el resto de los constituyentes en su valoración del «Judiciary for effective protection of property and vested rights» ${ }^{45}$.

La protección que ofrece la judicial review se orienta en contra del legislador democrático que, en opinión también de todos los constituyentes, es el núcleo de toda posible desestabilización. No sorprende entonces oír en boca de uno de los más conspicuos defensores del ideario democrático como Jefferson, una visión especialmente negativa de los riesgos que encierra la Asamblea legislativa: «It should therefore guard us against their abuses of power within the field submitted to them ... The executive in our government is not the sole, it is scarcely the principal object of my jealousy. The tyranny of the Legislatures ist the most formidable dread at present, and will be for long years» ${ }^{46}$. Es patente, por tanto, la general desconfianza ante el legislador. Ya no es el Ejecutivo el único poder del que hay que protegerse, sino de la legislatura y de la omnipotencia a la que la empuja la conciencia de la plenitud de su legitimidad en una democracia representativa. La amenaza para la libertad y la propiedad de los particulares que de aquí se derivan, hacen anticipar a los constituyentes una cierta distancia respecto de la estructura de poder que estaban creando. Para Hamilton -en la sesión del 18 de junio de la Convención federal, en la que expuso su concepción del Estado y del Gobierno- la voz de Dios no se encuentra en lo que de la voz del pueblo refleja la legislatura, sino en «that of the judges in whom the requisite knowledge is combined with the requisite integrity and who, when invalidating an act of the legislature, do their duty as faithful guardians of the Constitution, where legis/ative invasions of it had been instituted by the major voice of the community" ${ }^{47}$.

\section{GRAN BRETAÑA}

El caso de Inglaterra ofrece, en la singularidad de su conformación jurídico-política, asimismo, la evidencia de la relación estructural existente entre la composición y funciones del órgano representativo y la existencia —en este caso inexistencia- de una jurisdicción constitucional.

Es evidente que la Constitución inglesa no sólo recoge el desarrollo de sus instituciones a lo largo de los siglos, sino también la indeterminada definición de las competencias y funciones de sus distintos órganos. La

45 Ch. G. HaInes, op. cit., I, pág. 202.

46 Cit. en Ch. G. Haines, op. cit., I, pág. 207.

47 Cit. en Gottraied Dietze, The Federalist: A Classic on Federalism and Free Government, Baltimore 1960, pág. 161. 
interdependencia y recíproca limitación de los mismos ha sido algo que, salvo muy contadas excepciones, nunca se estableció por ley, sino por medio de custom y convention; en todo caso normas y reglas no escritas - extralegales reguladoras de los procedimientos y relaciones entre los poderes del Estado ${ }^{48}$. Pero son reglas no escritas - producto del criterio de oportunidad y de los conflictos que entre los órganos de poder se van generando a lo largo de los siglos- y, por tanto, dejan siempre en la indeterminación la verdadera dimensión competencial y funcional de cada uno de los órganos que concurren en la unidad de poder político que es el Estado. A ello ha de añadirse, además, el independiente desenvolvimiento de la Common Law, lo que supone una dificultad adicional a la hora de establecer con un mínimo de precisión los ámbitos dispositivos del Parlamento y de los jueces, así como las relaciones y vínculos entre ellos.

Todavía durante los Tudor la legislación se incluía vagamente en la prerrogativa real, aunque el Parlamento habia ido extendiendo el fuero orgánico de su función hasta condicionar el ejercicio de las prerrogativas legislativas de la Corona al consentimiento parlamentario. No obstante, "the residuum of legislative power was still felt in a general way to be in the King» "49. La separación entre King in Council y King in Parliament no era estricta y nítida. Por lo demás, tampoco el Parlamento era un órgano claramente definido en cuanto a sus funciones y competencias. El Parlamento no era un órgano exclusivamente Legislativo, del mismo modo que la legislación no era exclusiva de él, no sólo por las funciones judiciales ejercidas por el Parlamento, sino también por las funciones legislativas asumidas por el Privy Council, especialmente bajo los Tudor.

Subsiste en Inglaterra desde el final de la Edad Media una fusión entre los tribunales ordinarios y el Parlamento, correspondientemente a la indistinción medieval -y tradicionalmente anclada en la concepción inglesa del derecho- entre declaración y creación de la ley. El legislador medieval es un «registrador» del derecho. La ley tiene naturaleza objetiva, de tal forma que la función del legislador es descubrirla: «Law was to an important extent conceived by both governors and governed as a subject of science, capable of being learnt by special study, but not capable of being altered by the mere arbitrary will of governments ${ }^{50}$. En consonancia con

48 Para Dicey y las conventions son "rules for determining the mode in which the discretionary powers of the Crown ought to be exercised" (A. DiCEY, An Introduction to the Study of the Law of the Constitution, 9. ${ }^{a}$ edición, pág. 418). Las Constituciones son instrumentos de cooperación que no operan por si solas, sino a través de los hombres. "The constitutional conventions are the rules elaborated for effecting that co-operation" (Sir Ivor Jennings, The Law and the Constitution, 5. ${ }^{a}$ edición, Londres 1959, pág. 82).

1962, pág. 316.

49 Ch. H. MclLwain, The High Court of Parliament, 2. ${ }^{\text {a }}$ reimpresión, Conneticut

${ }_{50}$ R. SiDGWICK, The Elements of Politics, 2. ${ }^{a}$ edición, págs. 652-53. 
este concepto de ley, el Parlamento más que un órgano creador del derecho es un órgano declarador del mismo. Es decir, un tribunal. Como señala POLLOCK: "Law-making is not yet regarded as a distinct branch of sovereign power, external to the judicial authority ${ }^{51}$.

De esta situación en origen se deriva, a lo largo de los siglos siguientes, una innegable autoridad de los jueces sobre las leyes emanadas por el Parlamento. Autoridad correspondiente a la que mantiene la Common Law sobre la Statute Law. Ello es patente en la estructura del derecho inglés durante estos siglos (prácticamente hasta el siglo XVII) ${ }^{52}$. En el caso Sheffield $v$. Ratcliff (1615) el juez Hobart, respondiendo a la pregunta de cuál sea la regla por la que se rigen los jueces para la explicación de los términos de las leyes, dirá que «it was by that liberty and authority that judges have over laws, specially over Statute laws, according to reason and best convenience, to mould them to the truest and best use» ${ }^{53}$. Supremacía de los jueces, no sólo atendiendo al origen y esencia del Parlamento inglés como High Court of Parliament, también debido a la prevalencia y superioridad de la Common Law -entendida como una ley fundamental- sobre la Statute Law. La idea de la Common Law entendida como ley fundamental, subyace en el Fourt Institute de Coke, cuando afirma que «To know what the Common Law was before the making of any Statute (...) is the very lock and key to set open the windows of the Statute" ${ }^{54}$. Coke pretendia generalizar esta doctrina elevando a rango doctrinal una serie de precedentes de sentencias judiciales que rechazaron leyes del Parlamento ${ }^{55}$. El carácter de ley fundamental de la Common Law puede deducirse igualmente de los términos del procedimiento contra Clarendon (1667), en el que el juez Sir Heneage Finch (posteriormente, Lord Chancellor) afirma que "And tho' I know not what the Legislative Power of a Parliament cannot do, yet it is not

51 Sir F. Pollock, First Book of Jurisprudence, cit. en Ch. H. Mclilwain, op. cit., pág. 327.

52 Ver Carleton K. AlLen, Las Fuentes del Derecho inglés, Madrid 1969, página 649 y ss.

${ }_{53}$ Cit. en C. K. AlLeN, op. cit., pág. 647, número 51.

${ }_{54}$ Cit. en Ch. H. Mcllwain, op. cit., pág. 268.

${ }_{55}$ Tal parece ser el caso por el que se rechazó la cláusula principal de la ley «De Donis» por medio de una sentencia judicial («The class legislation of Parliament was defeated by the national legislation of the judges», Ch. H. MclLwAIN, op. cit., pág 267). Sin embargo, la idea de un "Common Law» fundamental, reconocido como soberano por los jueces, como mantiene MclLwaIN, requiere cierta relativización. No es posible afirmar que la finalidad del Statute Law era interpretar y aplicar el derecho fundamental recogido en la Common Law, sin poder modificarlo o derogarlo. Como mantiene C. K. ALLEN, ya en el siglo xV reconocían los tribunales una capacidad preeminente al rey y al Parlamento para novelar el derecho. Con todo, sí puede afirmarse que la indiscutible autoridad del Statute Law no tiene lugar de forma plena hasta fines del siglo xv, comienzos del XVI (ver C. K. ALLEN, op. cit., pág. 643). 
in the Power of the Parliament, King, Lords nor Commons, to declare anything to be Treason, which is not in the Common Law Fenoly before" ${ }^{56}$.

A esta tradición de prevalencia de la Common Law respecto de la Statute Law y, consiguientemente, de los jueces respecto de las funciones legislativas del Parlamento, es a la que pertenece el célebre pasaje del juez Coke en el Bonham's Case: "And it appears in our books, that in many cases, the common law will controul acts of Parliament, and sometimes adjudge them to be utterly void: for when an act of Parliament ist against common law and reason, or repugnant, or impossible to ber performed, the common law will controul it, and adjudge such acts to be void" ${ }^{57}$.

Prescindiendo de la polémica sobre el significado general que puede conferise a los casos y a los obiter dicta de los jueces en ellos a lo largo de un tan largo período de tiempo, lo que sí puede afirmarse es que la contraposición entre el rey (prerrogativa de la Corona) y el Parlamento, en cuya dinámica se originan las convenciones que regulan - tan imprecisamente- sus ámbitos dispositivos, se extiende también al derecho. La common law and reason a la que los common lawyers quieren saber sometido el Statute Law ( $y$, por ende, al Parlamento), es el mismo al que jueces y commoners quieren ver sometido al rey. Es, en todo caso, "the artificial reason and judgement of law» ${ }^{58}$ por las que ha de regirse, según Coke, la actuación del rey, siguiendo el dictum de Bracton, «quod Rex non debet esse sub homine set sub deo et lege» ${ }^{59}$.

Durante el siglo XVII en Inglaterra concurren varias tradiciones determinantes para el entendimiento de las instituciones jurídicas y políticas de su orden constitucional. Por un lado, como señala MAITLAND, persiste una imprecisa noción de soberanía, heredada de la época medieval, que no incluye la exigencia de que en todo Estado "there must be some man or some body of men above all law» ${ }^{60}$. Concepción que se reprodujo en un entendimiento de la ley "as existing independiently of the will on any ruler, independiently even of the will of God; God himself was obedient to law;

56 Cit. en Ch. H. Mcllwain, op. cit., pág. 306.

57 Frederic WILLIAM MAITLAND, The Constitutional History of England, Cambridge 1912, pág. 301.

${ }_{58}$ F. W. MaItLAND, op. cit., pág. 269.

59 Aún con mayor claridad expondrá Coke la supremacía de la Common Law sobre la prerrogativa real al afirmar que «The king by his proclamations, or other ways, cannot change any part of the common law, or statute law, or de customs of the realm... the king had not prerrogative but that which the law of the land allows him" (cit. en F. GarzonI, Die Rechtstaatsidee im schweizerischen Staatsdenken des 19. Jahrhunderts, Zürich 1952, pág. 25).

60 F. W. MAITLAND, op. cit., pág. 101. De aquí que, en su tiempo, la teoría hobbesiana del poder politico encarnado en un soberano o en una asamblea soberana supuso un quiebro radical respecto de la concepción tradicional del poder político. 
the most glorious feat of his omnipotence was to obedy the law" ${ }^{61}$. Por otro lado, y consecuentemente con la pervivencia de concepciones medievales sobre la ley y el derecho, la estructura juridico-política se caracteriza por una fusión de las funciones judiciales y legislativas «of the manifest $a b$ sence of any clear distinction between a judgement and a law, between judicature and legislatiton" ${ }^{62}$. Situación que persiste en gran medida todavía en las polémicas relaciones entre jueces y Parlamento durante el siglo XVII. Y, por último, la imprecisa y cambiante definición de la "prerrogativa real» y la gradual reducción de su ámbito dispositivo frente a la expansión funcional del Parlamento.

De la concurrencia de estas tres tradiciones, y de la alianza de los jueces y el Parlamento contra la resistencia de la prerrogativa real a seguir transfiriendo capacidad decisoria en favor de los Comunes, se opera durante el siglo XVII una redefinición del orden constitucional y de la naturaleza de los órganos que lo integran. Ello se sustancia en la nueva estructura constitucional salida de la guerra civil y caracterizada por la soberania del Parlamento.

Cierto que la primera formulación de la supremacía del Parlamento corresponde a Thomas SMITH ${ }^{63}$, pero es muy probable que éste no tuviera plena conciencia del alcance que esta noción tenia. Cuando Smith dice que el poder del Parlamento es absoluto, parece evidente, como observa MCILLWAIN, que se está refiriendo al poder judicial del mismo. Esto es, que la decisión («judicial») del Parlamento no es apelable ${ }^{64}$. No obstante, la idea se extendió rápidamente durante la guerra civil y posteriormente, de tal forma que, con la restauración de la Monarquía a la muerte de Cromwell, la Constitución inglesa se reorganiza en torno a la institución del Parlamento. El enfrentamiento entre el Parlamento y la prerrogativa real durante los Stuart, llevó a la limitación de esta última por medio de la consolidación de la rule of law, encarnado en la soberanía del Parlamento ${ }^{65}$. Por otro lado, los poderes que todavía pertenecía a la prerrogativa real después de la revolución, van siendo gradualmente transferidos a partir de 1688 del rey a los ministros, terminando por quedar integrados en el ámbito dispositivo de los Comunes, toda vez que es esta Cámara la que pasará a controlar definitivamente a los ministros. Como señala DICEY, en

61 F. W. MaITLAND, op. cit., pág. 101.

62 Ch. H. Mcllwain, op. cit., pág. 290.

63 En su obra The Commonwealth of England and the manner of government thereof, de 1585, expone T. SMITH: "The most high and absolute power of the realm of England consisteth in the parliament... That which is done by this consent is called firm, stable and sanctum, and is taken for law» (cit. en F. W. MAITLAND, op. cit., página 255).

Ver Ch. H. Mclıwain, op. cit., pág. 128 ss.

65 Sir William R. ANSON, The Law and Custom of the Constitution, 4. edicion, Oxford 1935, pág. 36 ss., vol. I. 
dicho trasvase "The prerrogative of the Crown have become the privileges of the people" ${ }^{66}$.

El proceso hacia la consolidación de la soberanía del Parlamento se puede considerar formalmente iniciado con la célebre Declaración de 27 de mayo de 1642 por la que Lords and Commons responden al bando de Carlos I prohibiendo a sus súbditos obedecer las disposiciones del Parlamento encaminadas a formar un ejército ${ }^{67}$. Declaración en la que ambas Cámaras no sólo proclaman su autonomía respecto de la prerrogativa real, sino que se atribuyen a si mismas la suprema autoridad del reino. Resultado de este proceso, consolidado a finales del XVII principios del XVIII, fue la soberanía del Parlamento. Soberanía que era verdaderamente total, pues a su posición orgánica suprema en la estructura del Estado, se sumaba la irresponsabilidad de los miembros que lo componian frente al electorado, toda vez que la corrupción de los prodecimientos electorales, la arbitrariedad en la creación de circunscripciones electorales y el censitarismo del derecho de sufragio, hacian de la naturaleza representativa del Parlamento inglés una ficción. Es evidente que la omnipotencia de la institución parlamentaria hubiera debido producir una lógica intranquilidad, en lo que afectase a la libertad y propiedad individuales, habida cuenta la limitada dimensión de poder concentrado en una sola institución orgánicamente incontrolable y socio-políticamente irresponsable. Como señala LOWELL, los instrumentos jurídicos con los que el derecho inglés provee a la defensa de los derechos individuales frente al poder político (desde las correspondientes cláusulas de la Charta Magna hasta el Bill of Rights), es decir, aquellos "great bulbarks of English liberty (...), were very effective in shielding the people against attacks on the part of the King (...) But they have put no check upon legis/ation. To so great an extent is this true, that private property in England is, on the whole, less secure form attack on the part of government to-day than it was at the time of the Stuarts" ${ }^{68}$.

A. DiceY, op. cit., pág. 461.

${ }^{67}$ En dicha declaración se enuncian ya la multiplicidad de poderes que concurren en el Parlamento y, consecuentemente, la supremacia que ello implica para la institución parlamentaria: «The High Court of Parliament is not only a Court of Judicature, enabled by the Laws to adjudge and determine the Rights and Liberties of the Kingdom against such Patents and Grants of this Majesty as are prejudicial thereunto (...), but it is likeweise a Council to provide for the necessity, to prevent the inminent Dangers, and preserve the public Peace and Safety or the Kingdom... and what they do herein hath the same of Royal Authority, although his Majesty seduced by evil Council, do in his own Person oppose or interrumpt the same, for the Kings Supream and Royal pleasure is exercised and declared in this High Court of Law and Council after a more eminent and obligatory manner, then it can be by any personal Act or Resolution of his own" (cit. en Ch. H. Mclıwaln, op. cit., página 390).

${ }_{68}$ LowelL, Essays on Government, cit. en Ch. H. MclLwaIN, op. cit., pág. 366. 
En el siglo xvIII culmina el proceso de hegemonización orgánica del Parlamento en la Constitución inglesa, recibiendo la sanción de la doctrina constitucional oficial en el célebre pasaje de BLACKSTONE «if the parliament will positively enact a thing to be done which is unreasonable, I know of no power that can control it», rechazando a continuación toda pretensión por parte de los jueces de controlar y, en su caso, rechazar las leyes elaboradas por el Parlamento, lo que "would be subersive of all government» ${ }^{69}$.

Una situación constitucional como la inglesa en el siglo xVIII hubiese debido lógicamente plantearse la necesidad de alguna garantía de los derechos individuales frente al legislador ilimitado que encarnaba el Parlamento, máxime cuando la tradición jurídica inglesa proporcionaba argumentos doctrinales y jurisdiccionales para poder estructurar desde ellos mecanismos judiciales de control de la labor legislativa del Parlamento ${ }^{70}$. El hecho de que, en la Inglaterra de los siglos XVIII y XIX, la sociedad civil no contemple la necesidad de protegerse frente a un órgano Legislativo de tal grado de omnipotencia, se debe, obviamente, a que dicha omnipotencia no era percibida como amenazadora para el orden y los intereses dominantes. No se veía en el Parlamento a un eventual reformador del statu quo socio-económico ${ }^{71}$. Dado que, no obstante, el Parlamento era —con los matices apuntados- efectivamente omnipotente, la condición que posibilitaba la compatibilidad de su omnipotencia con el mantenimiento del orden establecido, era únicamente explicable como la autolimitación derivada de la composición sociológica del Parlamento.

Como indica LOEWENSTEIN, hasta la reforma electoral de 1867 sólo puede considerarse al Parlamento inglés como urepresentante" de la "voluntad popular" en el muy laxo sentido de haber sido, para la construcción estatal de Inglaterra, el instrumento de las capas sociales dominantes, en cada período ${ }^{72}$. En otros términos, hasta 1867 Inglaterra es -desde una óptica de sociología política - una oligarquía parlamentaria; un sistema juridico-político en el que la clase socioeconómicamente dominante coincide, sociológicamente hablando, con la clase política o clase en el poder. En la historia constitucional inglesa el Parlamento es el órgano que protagoniza el enfrentamiento con la prerrogativa de la Corona, hasta adquirir el monopolio Legislativo correspondiente a la supremacía orgánica. Pero la posición que en la estructura de poder político va adquiriendo el Parlamento, es en todo momento independiente del proceso democratizador de la representación que incorpora. Es una posición que se define exclu-

69 Sir William Blackstone, op. cit., I, pág. 91.

70 Argumentos doctrinales y jurisdiccionales que, en cambio, sí fueron recogidos y utilizados por los constitucionalistas norteamericanos para introducir la revisión judicial de las leyes.

${ }^{71}$ Ver n. 37.

72 Karl Loewenstein, Beiträge zur Staatssoziologie, Tübingen 1961, pág. 35. 
sivamente frente a la Corona. En este sentido el Parlamento se caracterizó por una actitud de subordinación frente a los Tudor y por una clara oposición frente a los Stuart. No obstante, estos cambios en la orientación institucional del Parlamento no obedecían a modificación alguna en su composición sociológica. Por el contrario, en el periodo que abarcan las dos dinastías, Tudor y Stuart, hasta 1640 , el Parlamento se caracterizó por una "completa independencia respecto del electorado" ${ }^{73}$. La indiferencia electoral en la composición del Parlamento es, precisamente, el rasgo esencial para entender la actuación del mismo.

Una vez iniciada la Restauración a la muerte de Cromwell, y ya consolidada la posición jurídico-política del Parlamento respecto de la prerrogativa real, la Corona intentará recuperar el dominio perdido sobre aquél por medio del control sobre su composición interna, lo que efectuó introduciendo a la aristocracia en su seno. De este modo, el denominado Parlamento de los Caballeros, con su larga duración (1660-1678), fue, por lo que respecta a su composición sociológica, la expresión más alejada de la voluntad popular en la historia inglesa.

El propio sistema representativo inglés es asimismo un producto de la continuidad institucional que caracteriza a toda la Constitución. Desde $1295^{74}$ en que se convoca el que sería denominado "Parlamento modelo», se continuó el procedimiento de convocar a los condados y a ciertas ciudades. La representación del reino en Commons fue siempre una condición conferida a territorios. Otra cuestión distinta era a través de quién se articulaba la representación de los condados y de las ciudades. Los representantes habían de ser obviamente personas naturales, elegidas por colectivos restringidos, tanto en los condados como en las ciudades. Era pues una representación en segundo grado y censitaria. Era de segundo grado porque, si bien todos los condados eran demarcaciones electorales, en los que se elegían dos caballeros por condado, no pasaba lo mismo con las ciudades. No todas ellas tenian representación en los Comunes. Pero $-\mathrm{y}$ aquí reside una de las singularidades históricas del sistema inglés de representación- tampoco la selección de las ciudades a las que conferir representación en los Comunes se efectuaba por criterio racional alguno, en principio porque ni siquiera era un criterio único. Si la condición representativa se hubiese atribuido a las ciudades según un único criterio selectivo, hubiese tenido el procedimiento cierta racionalidad, independien-

73 K. Loewenstein, op. cit., pág. 41.

74 Simón de Monfort convocó - después de la batalla de Lewes, el 14 de mayo de 1264- un Parlamento, al que sólo fueron convocados, entre las dignidades eclesiásticas y militares, aquellos obispos, abades y barones que eran aliados del partido en el poder. Pero entre los commoners, ordenó a cada sheriff enviar dos caballeros por cada shire, ordenando lo mismo a las ciudades y boroughs. La novedad de este Parlamento fue, precisamente, la presencia de villanos y burgueses (ver F. W. MaitLand, op. cit, pág. 73). 
temente del eventual carácter atrabiliario del mismo. Pero la realidad fue muy otra. Las ciudades designadas para concurrir a los Comunes a través de representantes, eran aquellas que bien por patente real, o por costumbre y tradición (by prescription) o por la propia voluntad del Sheriff, recibian la convocatoria real para acudir a Parlamento. El resto de las ciudades se las consideraba representadas a través de los condados en las que estaban situadas $^{75}$.

A lo largo de los siglos, ni el número de ciudades representadas en los Comunes permaneció constante, ni tampoco la identidad de las mismas. Cuáles sean las ciudades que concurran como tales a los Comunes, y cuál sea su número, son datos sometidos a grandes fluctuaciones. Causas de estas fluctuaciones durante la Edad Media, y aún posteriormente, eran las ciudades que preferian decaer en este derecho, a causa de los gastos que suponían las dietas con que tenian que proveer a los representantes para cubrir los costes de viaje y estancia en la ciudad donde se celebrase el Parlamento ${ }^{76}$. Gastos que, para la ciudad, no conllevaban contraprestación alguna, antes al contrario, ya que la condición de ciudades representadas las obligaba al pago de tributos más elevados que los pagados por los $\operatorname{condados}^{77}$. Otra de las razones en la indeterminación y fluctuación en el número de ciudades con representación en el Parlamento era la propia discrecionalidad real en la concesión de patente o franquicia representativa ${ }^{78}$. Esta capacidad discrecional de la Corona fue un instrumento muy utilizado, tanto por los Tudor como por los Stuart, para cumplir los objetivos centralizadores de estas dinastías. La mayoría de las veces la concesión de la franquicia real obedecia menos a la significación objetiva de la ciudad a la que se concedía (número de habitantes, interés comercial o industrial...), que a la docilidad respecto de la voluntad real ${ }^{79}$. Ello condujo a que áreas urbanas verdaderamente insignificantes adquiriesen el derecho a enviar representantes a los Comunes, mientras que otros centros urbanos, que Ilegaron a ser auténticos núcleos industriales y comerciales

75 Julius HatscheK, Englisches Staatsrecht, Tübingen 1905, vol. I, pág. 290.

${ }^{76}$ Si un borough enviaba representantes al Parlamento, tenía que sufragar los gastos. De esta forma en 1368 el borough de Torrington solicita con éxito del rey la exención de enviar representantes. Es muy probable que otros boroughs consiguieran otro tanto por medio de negociaciones con el sheriff (ver F. W. MAITLAND, op. cit., pág. 174).

${ }_{77}$ Los condados eran gravados en $1 / 15$, mientras que los boroughs representados lo eran en $1 / 10$ (ver J. HATSCHEK, op. cit., pág. 290, vol. 1).

78 Este poder permitió a la Corona dominar a la Cámara de los Comunes, aunque no fue ejercido con liberalidad hasta la llegada de los Tudor (ver F. W MaitLAND, op. cit., pág. 174).

${ }^{79}$ Sir William R. ANSON, op. cit., vol. I, pág. 134. 
(tales como Manchester, Birminghan, Sheffield...), careciesen de este derecho hasta la primera gran reforma electoral de $1832^{80}$.

La capacidad real en la concesión de franquicia representativa llegó con los Stuart a tal grado de arbitrariedad, que contribuyó en no pequeña medida a la radicalización en el enfrentamiento entre James I y los Comunes. Al respecto intervendrá COKE, recordando que "All which are respectively elects by the shires or counties, cities and boroughs, by force of the King's writ "ex debito justiciae", and none of them ought to be ommitted; as these represent all the commons of the whole realm and trusted for them, and are in number of this time $493 "{ }^{81}$. Términos en. los que, implicitamente, se niega al rey la capacidad para crear nuevos boroughs. En el mismo sentido hay que entender la protesta del Parlamento, en una resolución de 11 de diciembre 1645 (el «Parlamento Largo») en la que se expone "That for time to come, no new power shall be granted by the King to any city or borough to send citizens or burgesses to the Parliament of England, saving only by acts Parliament, upon Petition of the House of Commons, assambled in the Parliament of England" ${ }^{82}$.

Aparte de la creación arbitraria de circunscripciones hay que resaltar la absoluta falta de planificación y la profunda desigualdad que caracterizaba la atribución de representatividad, tanto entre las mismas ciudades y boroughs, como a éstos respecto de los distritos rurales ${ }^{83}$. Por otro lado, el procedimiento electoral que se seguia para elegir a las personas encargadas de titularizar la representación de los distintos ámbitos territoriales (urbanos y rurales), propiciaba toda suerte de irregularidades y manipulaciones. Hay que tener en cuenta que el procedimiento electoral inglés se ha regido siempre por el principio de doble fase de la elección: la pre-elección o nominación de los candidatos por los electores y la elección propiamente dicha, en el caso de que haya más candidatos nominados que cargos a elegir ${ }^{84}$. Sólo en este último caso tenía lugar la elección o poll, es decir, el recuento numérico de los votos obtenidos por los distintos candidatos nominados.

En cuanto al derecho de sufragio activo, éste era entendido en la tradición jurídico-política inglesa como un derecho privado, en contrapo-

${ }^{80}$ Como señala ANSON, "It is enough to say that is was alleged and with apparent truth, at the end of eighteenth century, that 360 members were virtually returned by the influence of 160 persons; it is certain that the Reform Bill of 1832 had to deal with nine boroughs in which the number of voters did not exceed fifteen" (Sir William R. ANSON, op. cit., vol. I, pág. 134).

81 Cit. en J. HATSCHEk, op. cit., vol. I. pág. 291.

82 J. HATSCHEK, op. cit., vol. I, pág. 291.

83 Shires y condados se encontraban sobrerrepresentados respecto de las ciudades. Igualmente imperaba la más crasa injusticia electoral entre los distritos electorales urbanos (ver J. HATSCHEK, op. cit., vol. I, pág. 251).

${ }_{84}$ Ver J. HATSCHEK, op. cit., vol. I, págs. 274 y 280. 
sición a la europeo-continental, en la que la elección queda entendida como participación y, por tanto, como responsabilidad en la composición y formación del órgano estatal. De aquí que en el continente el elector pudiese llegar a ser contemplado como un órgano del Estado ${ }^{85}$. En Inglaterra, por el contrario, aparece en primer plano el interés y la dimensión privados. Ello parece derivar de la concepción medieval, en la que el régimen de propiedad de la tierra informa toda la estructura pública ${ }^{86}$. La reglamentación de las distintas formas de tenencia de la tierra determina el conjunto de la organización pública «a quite perfect feudal arrangement, then all courts, all judicial and governmental organization, should be determined by tenure" ${ }^{87}$. Consecuentemente es la tenencia de la tierra, la regulación del derecho de propiedad sobre la tierra de donde deriva la habilitación y la condición de elector del propietario. Siguiendo el razonamiento de Lord Holt, en el célebre caso Ashby $v$. White (1705), "The election of knights belongs to the freeholdres of the county and is an original right vested in and inseparable from the freehold and can no more be served from the freehold, than the freehold itself can be taken away... but still the right of election is an original right incident to and inseparable from the freehold" ${ }^{88}$. El derecho activo de voto es algo que se pliega por completo a las modulaciones del derecho de propiedad ${ }^{89}$. En los condados era una condición inherente al freehold ${ }^{90}$. Puede afirmarse entonces la naturaleza condicional y adjetiva del derecho de sufragio. Como subraya Lord BROUGHAM «... It is not a property but an incident to a property» ${ }^{91}$. Por tanto, el derecho activo de sufragio es, en el derecho inglés, una condición incidental a la propiedad privada de la tierra.

Como consecuencia a la naturaleza jurídico-privada del derecho de sufragio el procedimiento electoral queda en manos de organizaciones privadas: los caucus de los partidos de cada demarcación electoral. Agrupaciones locales de los partidos que se encargan de confeccionar las listas electorales, procurando cada una de éstas incluir en ellas a sus potenciales votantes, excluyendo por el mismo motivo a los presumibles votantes del

85 Como la teoria del órgano en JELLINEK, o la idea de «poder electoral» en Hauriou.

${ }^{86}$ Como señala F. W. MAITLAND, op. cit. «In the Middle Ages land law is the basis of all public law, pág. 38.

${ }^{87}$ F. W. MAITLAND, op. cit., pág. 38.

88 Cit. en J. HATSCHEK, op. cit., vol. I, pág. 256.

${ }^{8}$ J. HATSCHEK, op. cit., vol. I, pág. 260.

so Freehold y freeholder remite a la modalidad medieval de tenencia de la tierra en villanaje, pero sin que implique condición de villano del teniente, sino la condición de teniente libre (freeholder). Es una modalidad de tenencia que implicaba la posesión de ciertos derechos por el teniente, aunque tales derechos nunca pudiese ejercerlos contra el «señor». A este tipo de tenencia es a lo que el derecho inglés denomina freehold y a su titular freeholder (F. W. MAITLAND, op. cit., pág. 35).

91 J. HATSCHEK, op. cit., vol. I, pág. 256. 
otro partido. Las listas confeccionadas por los distintos partidos se discuten ante un revisor oficial en un procedimiento contradictorio, en el que el agente de cada partido objeta la lista de sus oponentes y defiende la propia, hasta llegar a la confección de una lista electoral única para el distrito correspondiente (el llamado pairing off) ${ }^{92}$.

Todo ello daba pie a un sinfín de manipulaciones y prácticas ilegales, de tal forma que la confección del censo electoral quedaba de hecho en manos de las oligarquías locales de los partidos, que eran los que negociaban y acordaban entre sí el número y orientación partidista de los votantes en cada distrito. Hay que añadir que la votación de los candidatos era pública (a mano alzada o por voto oral) y, por tanto, transparente a efectos de control sobre la emisión del voto, previamente comprado al elector por los agentes del caucus local ${ }^{93}$.

La consecuencia era el absoluto control por las oligarquías locales del procedimiento electoral, de donde derivaba que la representación de las circunscripciones urbanas - que, a su vez, en su gran mayoria habian sido creadas por el poder discrecional de la Corona, atendiendo a los intereses de la aristocracia rural- fuese materia de compraventa. Tanto los ricos comerciantes, como el propio Gobierno no dudaban en hacerse con esta mercancía al precio de mercado. Tampoco la aristocracia dudaba en asegurarse de este modo el patronazgo sobre estos distritos electorales. Se compraba el derecho a predeterminar los candidatos que serian elegidos ${ }^{94}$.

Se puede afirmar así que el sistema representativo en Inglaterra era un sistema de selección política en favor de los intereses socio-económicos dominantes. Así lo expondrá el propio William PITT en 1785 cuando, refiriéndose a la composición de los Comunes, afirme que "This house is not the representation of the people of Great Britain; it is the representation of nominal boroughs, of ruined and exterminated towns, of noble families, of wealthy individuals, of foreign potentates" ${ }^{95}$. Pretendiendo con esta acusación impulsar una reforma electoral que, sin ampliar el censo electoral, corrigiese la representación de meros intereses (que, necesariamente, habrian de ser sólo los intereses dominantes) en favor de criterios poblacionales más acordes a la realidad social de Inglaterra.

El acceso del Parlamento a la soberanía en la Constitución inglesa viene acompañado, desde una óptica de sociología política, por una férrea

92 Ver M. Y. Ostrogorski, La démocratie et l'organisation des partis politiques, 1903, vol. I, págs. 348 ss., 421 ss.

93 La votación secreta (ballot), aunque ya solicitada en la reforma electoral de 1832, no se conseguirá introducir hasta 1872, con la aprobación de la Ballot Act.

94 J. HATSCHEK, op. cit., vol. I, pág. 251.

95 Cit. en J. HatscheK, op. cit., vol. I, pág. 292. 
restricción de la representatividad del órgano a través del total control de la selección de sus miembros y, con ello, de los intereses socio-económicos representados. Soberanía política y omnipotencia legislativa del Parlamento han de entenderse partiendo de la sustancial limitación de la representatividad ocasionada por el tipo de correlación sociológica entre el Parlamento y el electorado ${ }^{96}$. Es esta subyacente determinación sociológica del Parlamento lo que posibilitará, tanto la convivencia política entre la supremacía del Parlamento y la prerrogativa de la Corona - aunque quizá sería más adecuado hablar de «prevalencia de la prerrogativa» ${ }^{97}$ en este período, con el consiguiente retraso en el proceso de parlamentarización del sistema político-, como de la pacificación de las relaciones entre Parlamento y sociedad civil. Naturalmente ello ocurre a expensas de una efectiva limitación de la capacidad legislativa y de actuación del Parlamento. Limitación que, al no proceder de un órgano exterior a él (los jueces, sometidos al Parlamento en virtud de la rule of law, en ningún caso podrían revisar la legislación, habida cuenta, además, de la ausencia de la Constitución escrita. Por otro lado, la Corona tampoco podía limitar al Parlamento, pues, desde el Billl of Rights de 1688, habia pasado de institución soberana a ser un órgano más del Estado), ha de tener necesariamente su origen en el propio Parlamento. Se trata de una implícita voluntad autolimitadora, resultado de la identidad entre los intereses representados en la Cámara de los Comunes y los intereses dominantes en la sociedad civil inglesa. Armonia cuya manifestación institucional más patente es la ar-

96 Ver K. LOEWENSTEIN, op. cit., pág. 38.

97 Convivencia tanto más paradójica, si se tiene en cuenta que desde la glorious Revolution de 1688 hasta mediados del siglo xIX se consigue frenar la parlamentarización del sistema político inglés, gracias a la autonomía que consigue fabricarse el Ejecutivo frente al Parlamento. Inicialmente (aprox. desde 1700) porque el Ministerio, gracias a la manipulación electoral, consigue garantizarse una mayoría en los Comunes y mantenerla. El premier Walpole (1721-1742) crea un verdadero sistema de manipulación y corrupción... Como además el monarca (de la casa de Hannover, Jorge I) se desentiende de la política, el Ministerio es, de hecho, independiente respecto del Parlamento (gracias a la manipulación electoral) y respecto de la Corona (debido a la indiferencia política de Jorge I). Hasta 1760 la dirección política del pais queda en manos de los intereses aristocráticos, en un Parlamento que, durante cincuenta años, será de mayoria whig ( $\mathrm{v}$. K. LOEWENSTEIN, op. cit. pág. 43). Cuando a partir de 1760, la Corona (Jorge III) ejerce la prerrogativa, decide recurrir a los mismos procedimientos que había venido empleando el Gobierno para mantener el gabinete frente al Parlamento. De este modo la Corona se encuentra en condiciones de mantener su ministerio en contra de la voluntad del Parlamento. Si la mayoría hostil al ministerio obliga a la Corona a la disolución de los Comunes, aquélla, gracias a la manipulación electoral, consigue siempre garantizar una mayoria al gabinete de su confianza. En general, puede afirmarse que «desde 1689 hasta el primer Reform Bill la regla es que un ministerio llamado por la Corona se encuentra en situación de garantizarse a sí mismo y a la Corona una mayoría en las elecciones generales" (K. LOEWENSTEIN, op. cit., pág. 44). 
monía política entre el Parlamento y la Corona, aunque la hegemonía política de esta última sobre el Gabinete durante este período sea un hecho que ralentiza considerablemente la plena parlamentarización del sistema político inglés. Existe pues una gradual determinación sociológica que afecta tanto a la organización de los poderes del Estado (parlamentarización), como a la eventual creación o no de determinadas instituciones (jurisdicción constitucional). No ofrece duda de que la continuidad protagónica de los intereses de la burguesía y aristocracia tiene su fundamento en la sociología electoral por la que se compone el Parlamento. Como señala LOEVENSTEIN, «Por un lado, las personalidades que se sentaban en la Cámara baja coincidían sociológicamente con el estrato gobernante o, más exactamente, eran el propio estrato gobernante... Por otro lado, el procedimiento de selección de estos representantes de los intereses de clase (...) tan manipulable, que la masa incontrolable del pueblo quedaba prácticamente excluida»" ${ }^{98}$.

Una vez conseguida la sintonía entre poder económico y poder político por medios electorales (censitarismo, manipulación del sistema representativo), garantizando así la exclusión de los órganos de decisión (Parlamento) de aquellos intereses - cuantitativamente mayoritarioseventualmente interesados en reformas del susbtrato socio-económico por via legislativa, resulta obvio lo innecesario de institución alguna encargada de revisar y, en su caso, rechazar la legislación del Parlamento. Si la «selección de los representantes se halla sociológicamente determinada, de tal modo que puedan acceder exclusivamente los exponentes de las clases dominantes" ${ }^{99}$, resulta evidente que la Cámara de los Comunes no legislará nunca en contra de los intereses que incorpora. Especialmente una vez que la idea de representación política viene a sancionar la completa autonomia funcional de la Cámara respecto de las vinculaciones locales, susceptibles de determinar los comportamientos de los diputados individuales.

En este período (siglo XVIII) es cuando se perfila el concepto de mandato representativo con el que dotar a los diputados, individualmente considerados, de total independencia frente a los distritos en los que han sido elegidos, culminando entonces el órgano Legislativo su total independencia. La coherencia institucional es, en este sentido, ejemplar. A la soberanía del Parlamento (monopolio y omnipotencia de la ley) se añade la desvinculación sociológica - vía manipulación electoral- de su función representativa de los intereses reales de la sociedad en favor de los intereses dominantes de las oligarquías $\mathrm{y}$, a todo ello, se añade por último la autonomía política del diputado respecto de las tradicionales instrucciones con que le proveían en el momento de la elección. Hay, como señala Esmein,

so K. LoenWNSTEIN, op. cit., pág. 44.

99 Ibidem, pág. 44. 
una intima relación estructural entre la soberanía del Parlamento y la disolución del vínculo imperativo que venía articulando la voluntad del diputado con las de los mandantes locales ${ }^{100}$.

La disolución del mandato imperativo tampoco fue algo realizado de modo inmediato en la Constitución inglesa. En su origen, la representación de las comunidades (rurales y urbanas) era, ante todo, un deber, con lo que estaban obligadas a elegir las personas encargadas de ejercerla (sufragando para ello los costes del procedimiento) y, asimismo, quedaban obligadas a dotarlas de los medios necesarios (dietas) para ejercer dicha función durante el tiempo que durase el Parlamento ${ }^{101}$. A ello hay que añadir el deber de aquel en quien recaía la elección de cumplir el mandato, para lo que se proveía de las consiguientes instrucciones. Todavía en las sesiones de los Comunes de 1614 se discute sobre cuándo puede un inglés elegido rechazar dicha elección. La respuesta a este punto es tajante: « $A$ man can not wave, unless chosen in another shire than were resident", ya que argumenta la respuesta "having a freehold in the shire he can not refuse to serve» ${ }^{102}$.

El cambio en la estima y valoración de un escaño en los Comunes comienza a operarse ya bajo los Tudor. La rica burguesía que se desarrolla bajo esta dinastía -en la que asimismo se consolida ya un sentimiento nacional ${ }^{103}$ - contempla la Cámara de los Comunes como algo valioso en lo que conviene participar. Lo que comenzó siendo un penoso y gravoso deber comunal, se transforma en un deseado y disputado derecho ${ }^{104}$. La representación de las comunidades deja de ser un deber de las mismas, para constituirse en un derecho del mandatario. El mandato se entiende entonces como una delegación pública de confianza o, lo que es lo mismo, un trust, lo que implica que el ejercicio de una función así calificado, ya no pueda ser ejercida por una especie de «apoderado» ${ }^{105}$.

100 Esmein, Éléments de droit constitutionnel français et comparé, $7 .^{a}$ edición, Paris 1921, pág. 93.

101 Estas obligaciones se encuentran claramente formuladas en el Modus Tenendi Parliamentum de fines de siglo XIV.

102 Cit. en HatscheK, op. cit., vol. I, pág. 271.

103 La correspondiente idea de «representación nacional" se encuentra ya formulada en Thomas SMITH en su De republica Anglorum, aparecido en 1583.

104 Ver F. W. MAITLAND, op. cit., pág. 240.

105 Por ello mismo los miembros de la Cámara de los Comunes no pueden delegar su función en terceros como, en cambio, sí pueden hacerlo los Lores que, al ejercer un derecho basado en una condición personal, podian hacerse representar por terceros. Como se expone en los comentarios al Reglamento de los Comunes del siglo XVII, "therefore the Lords have a greater Privilege, than the Members of the House of Commons because they can appoint other to serve in and supply their places in their absence, which the Commons cannot", debido a que los Lores temporales y espirituales siempre tuvieron y conservan uthe Liberty of Constituting their Procurators, whereas every menber of the House of Commons apperareth and 
No obstante, la aceptación del concepto de trust para calificar la relación del diputado respecto de los electores se vio aún enturbiada por la resistencia de la tradicional concepción imperativa del mandatario, como se refleja en el hecho de que los diputados continúan recibiendo las instrucciones en el momento de su elección o las recogen posteriormente. El mecanismo de las instrucciones perdura, aproximadamente hasta 1780 , desapareciendo definitivamente con la primera gran reforma electoral de 1832. En todo caso durante el siglo xvIli se mantiene una viva discusión entre los partidarios de entender la elección como una delegación de confianza trust y los que siguen viendo en ella un mero apoderamiento o procuración. En las sesiones de los Comunes de 1745 tiene lugar, por boca de Sir Walter YOUNG, la primera formulación precisa de la noción de representación política. The word attorney has ben artfully brought into the debate, as if members of this House were nothing more than the attorneys of the particular county, city, borough they respectively represented. But every one knows that, by our constitution after a gentleman is chosen, he is the representative, or if you please the attorney, of the whole people of England, and as such is at full freedom to act as he thinks best, for the people of England. He may receive, he may ask, he may ever follow the advice of his constituents; but he is not obliged, nor ought he to follow their advice, if he thinks it inconsistent with the general interest of his country" ${ }^{106}$. Es la misma concepción que BURKE expondrá posteriomente (1774) ante los electores de Bristol: "authoritative instructions, mandates issued, which the member is bound blindly and implicitly to obey to vote, and to argue for, though contrary to the clearest conviction of his judgement and conscience - these are things utterly unknown to the laws of this land, and which arise, from a fundamental mistake of the whole order and tenour of our constitution.

Parliament is not a congress of embassadors from different and hostile interests (...); but Parliament is a deliberative assembly of one nation, with one interest, that of the whole; where, no local purposes, not local prejudices, ought to guide, but the general good, resulting from the general reason of the whole. You choose a member indeed; but when you have chosen him, he is not member of Bristol, but he is a member of parliament» ${ }^{107}$.

Los representantes, los miembros de la Cámara de los Comunes son libres en el ejercicio de su función. Con ello se ultima la adaptación de todos los factores integrantes de la representación que permita subordinar la actividad legislativa a los intereses socio-económicos dominantes. In-

doth serve in the right of that County, City, Borough and Port for which he is elected and chosen, which being a Trust and confidence reposed in them, can be not more transferred from hime to a 3 person" (cit. en J. HATSCHEK, op. cit., vol. I, pág. 272).

106 Cit. en J. HAtScheK, op. cit., vol. I, pág. 273.

107 Ibidem, vol. I, pág. 274. 
tereses que «al ser los del estrato determinante para el Estado, son los que procuran validez a los de toda la nación; ya que la aristocracia y las capas sociales a ella asimiladas son el Estado» ${ }^{108}$. El Parlamento es la representación colectiva de la clase dominante, que se identifica con los de la nación, en la medida en que aquél es ex definitione el órgano representativo de la misma. A pesar del iusnaturalismo individualista que determina el pensamiento anglosajón de la época, el individuo, señala OSTROGORSKI, juega un papel tan escaso en la construcción de la sociedad inglesa, como inexistente la protección jurídica de que disponen las minorías en el Parlamento ${ }^{109}$.

Se puede decir que hasta la reforma de 1832 los mecanismos electorales y extraelectorales que estructuran el sistema representativo inglés, garantizan que la soberanía legal del Parlamento no contenga en sí nada de intranquilizador para el statu quo socio-económico. La función legislativa sufre el filtraje sociológico al que le somete los intereses que integran la propia Cámara de los Comunes, haciendo de suyo innecesario el control ex post facto al que, eventualmente, podrian haberla sometido los jueces. En todo caso, la revisión judicial de las leyes es un instrumento que no carece de antecedentes en la Constitución inglesa. De hecho, los precedentes juridicos ingleses fueron elementos doctrinales de peso para la creación de la judicial review norteamericana. Tampoco puede alegarse, como explicación de la inexistencia del control judicial de las leyes en Inglaterra, la ausencia de una Constitución escrita. Los antecedentes históricos respecto de la validez del Statute Law confirman que el Common Law fue considerado inicialmente como una ley o derecho fundamental y, por tanto, susceptible de ofrecer el término comparativo y resistente frente al Statute Law. Si el control judicial de las leyes no se encuentra recogido en la Constitución inglesa, ello obedece a lo innecesario que sería un instrumento jurídico-político, cuya finalidad es la limitación de la capacidad reformadora de los legislativos, en un orden constitucional en el que dicho control se opera por mecanismos que afectan a la propia edificación del órgano.

La situación de la Constitución inglesa a este respecto no cambiará tras la primera gran reforma electoral de 1832. Dicha reforma supone únicamente el relevo en el Parlamento de la hasta entonces dominante aristocracia por una burguesía industrial, políticamente madura como para asumir sin sobresaltos el protagonismo Legislativo. Es la clase de los fabricantes y empresarios, los industriales burgueses o manufacturers. El nuevo empresario «era todo menos un reformador político. También él estaba identificado con la seguridad de la propiedad, el principio dominante de la

109 M. Y. Ostrogorski, op. cit., vol. I, pág. 6. 
Constitución inglesa" ${ }^{110}$. La nueva clase política mantiene la continuidad en los principios orientadores de la legislación anterior. La experiencia de la Revolución francesa aparta a la burguesia inglesa de la ideología democrática, susceptible de introducir en el Parlamento intereses contrarios a la propiedad y la riqueza. Por ello pretende el relevo de la aristocracia, pero sin apelar para ello a las capas populares, cuya ignorancia y subordinación política pretende perpetuar.

La única forma de crearse un acceso a la Cámara de los Comunes será, por tanto, a través de la reforma electoral. Reforma que no supuso ampliación sustancial alguna del derecho de sufragio. Lo único que pretendía era - manteniendo el censitarismo existente- acabar con la irracional distribución territorial de la representatividad, de modo que, conservando la misma proporción de electores en términos absolutos, se incrementase la participación que en ella correspondiese a la burguesía industrial. La modificación esencial introducida por el Reform Bill de 1832 consistió «en la extensión del derecho de sufragio a la propiedad mueble, en lugar de centrarla exclusivamente en la propiedad real» "11. Los reformistas no pretendían una democratización de la Constitución. El objetivo de la reforma era únicamente un cambio sociológico en la titularidad del derecho electoral (nunca una ampliación sociológica de la misma). La reducción del poder electoral de la aristocracia, en favor de la burguesia, era sólo un relevo de la clase dominante, sin recurrir a métodos revolucionarios. Como los define DICEY, «l speak of the middle classes -of those hundreds of thausands of respetable persons- the most numerous, and by far the most wealthy order of the community s" ${ }^{112}$.

\section{ALEMANIA}

El modelo de desenvolvimiento alemán se caracteriza; ante todo, por su marcado carácter doctrinal y teórico, al que se contrapone un desarrollo político e institucional prácticamente mínimo. Alemania -0 , mejor dicho, el conjunto de los Estados alemanes- entran en el siglo xix de la mano del absolutismo.

La práctica desaparición de los órganos representativos del constitucionalismo medieval que acompaña la aparición del Estado moderno

110 K. Loewenstein, op. cit., pág. 74.

111 lbidem, pág. 79.

112 A. DiCEY, Lectures on the relation between law and public opinion in England during the nineteenth century, London 1905, vol. II, pág. 600 . 
bajo forma de Estado absoluto, tiene su adecuado reflejo en la suplantación de la ley por el "reglamento» (ordenanza real). El proceso de expulsión de la ley por la ordenanza concluye con la desaparición de aquélla a manos del poder normativo del rey. Esta situación en la creación del derecho coincide con la separación entre Estado y sociedad, entendidos durante el absolutismo como dos órdenes incompatibles. El Estado es esencialmente «Gobierno», esto es, el poder Ejecutivo. La gradual penetración de la sociedad en la armadura ejecutiva que es el Estado, empieza a efectuase en Alemania al final de las guerras napoleónicas. Es entonces cuando surgen formas políticas de compatibilidad entre Estado y sociedad. A éstas pertenece el modelo alemán: la monarquía constitucional ${ }^{113}$. Es una forma politica del siglo $\mathrm{x} \mathrm{x}$ caracterizada por una situación de equilibrio transitorio en la dialéctica entre Estado y sociedad ${ }^{114} \mathrm{y}$, por tanto; inmersa en un proceso «socializador», que habrá de ser permanentemente neutralizado por la afirmación del poder Ejecutivo, en tanto que titular del principio estatal. Por tanto, frente a las Cámaras, que según L. $v$. STEIN son el órgano a través del que la sociedad se apodera del Estado ${ }^{115}$, habrá de defenderse la preeminencia del principio estatal, identificado aquí con el poder Ejecutivo.

Este planteamiento general se ve intensificado por el rechazo, general en la doctrina juridico-pública alemana del siglo XIX, de la separación de poderes, como atentatorio al principio más fundamental de unidad de poder del Estado ${ }^{116}$. El principio de unidad estatal será el postulado doctrinal dominante en la construcción estatal de la monarquía constitucional alemana, con lo que ello supone de clara preeminencia del poder Ejecutivo. La contradicción que este contexto encierra, la expuso lúcidamente JELLINEK, para quien "sólo el que concibe a los poderes Legislativo y Ejecutivo como sujetos independientes, puede hablar de voluntad del Estado como distinta de la del Gobierno», mientras que si se parte de «la unidad del

113 La denominación no la tipifica como una forma de Estado en sí misma. Responde solamente a la organización politica transaccional en el proceso de constitucionalización alemán del siglo xIx (ver E. W. BOCKENFORDE, Der deutsche Typ der konstitutionel/en Monarchie, en el tomo de recopilación de sus ensayos "Staat, Geselschaft, Freiheit", Frankfurt 1976, pág. 130).

114 Ver E. W. BOCKENFÖDE, Gesetz und gesetzgebende Gewalt, Berlin 1969, pág. 151.

Lorenz von STEIN, Geschichte der sozialen Bewegung (1. ${ }^{\text {a }}$ ed. 1850), München 1921, vol. II, pág. 41.

${ }_{116}$ Es algo explícito no sólo en Stahl —quien en cuanto que defensor convecido del "principio monárquico", no supone sorpresa alguna-, sino también en Mohl y Gneist. Para la generalización de esta posición en el pensamiento jurídicopolítico alemán del siglo pasado, podemos remitirnos a Jellinek, quien afirma que "la doctrina jurídico-política alemana rechaza la teoria de la separación de poderes" (Gesetz un Verordnung [1. ${ }^{a}$ ed. 1887], reimpre. Tübingen 1919, pág. 367, n. ${ }^{\circ}$ 2). 
poder del Estado, habrá de reconocerse como voluntad estatal a la voluntad del poder Ejecutivo» 117.

El reconocimiento de la superioridad del Ejecutivo conllevaba en el área germana (Prusia, Baviera y el resto de los Estados alemanes) un cierto riesgo, debido a la fuerte implantación en ella del «principio monárquico». Principio que venia recogido en el artículo 57 del Acta Final del Congreso de Viena de 1820: «... todo el poder del Estado estará concentrado en el Jefe del Estado, pudiendo el soberano - a través de una Constitución estamental - quedar vinculado a la participación de los estamentos únicamente para el ejercicio de determinados derechos» ${ }^{118}$.

No obstante, las construcciones doctrinales del pensamiento juridico-publico alemán del siglo xIX no tienen por objetivo inmediato ni la defensa, ni el ataque del «principio monárquico» ${ }^{119}$. Responden aquéllas, más bien, al intento, no de cuestionar la soberanía monárquica, sino de conformar una mediación entre monarquia y soberania popular — con distintos matices políticos, dependiendo de los diferentes juristas-vinculado al intento de situar al Estado y a su actuación en un orden legal, en formas definidas y procedimientos previsibles ${ }^{120}$. El impulso democrático alemán era, en comparación con el francés, harto modesto. La emancipación social y política podía operarse desde arriba y debía hacerse sin desorden. Como dirá HELLER: "El sentido alemán del orden carece de la confianza rousseauniana en la fuerza generadora del caos" ${ }^{121}$. Hasta conspicuos representantes del ideario democrático de la época en Alemania, como Rotteck, descartan toda alteración del orden constituido en su lucha por los ideales «derecho y libertad». Ideales que «habrán de ser introducidos en la vida burguesa, accediendo a posición dominante por vía legal, no revolucionaria» ${ }^{122}$. En el propio pensamiento democrático de la época habia una ilimitada confianza en la institución monárquica. Hasta en el Parlamento revolucionario de Frankfurt de 1848 era muy escaso el número de partidarios de un derecho general de voto y de una amplia limitación de la prerrogativa real.

No ha de extrañar entonces que, en este marco histórico, la constitucionalización del sistema político alemán haya discurrido por cauces

117 G. JeLLineK, Gesetz und Verordnung, cit., pág. 367, n. ${ }^{\circ} 2$.

${ }^{118}$ Cit. en Hermann HeLleR, «Di politischen Ideenkreise der Gegenwart» (1926), en Gesammelte Schriften, vol. I, pág. 290, Leiden 1971.

119 Naturalmente, exceptuando a J. Stahl, cuya identificación y defensa de dicho principio es clásica. No obstante, es precisamente Stahl quien ha proporcionado a la doctrina jurídico-política la más precisa y universal definición del concepto de Estado de Derecho.

120 Ver E. W. BöckenfORDE, Der deutsche Typ der kanstitutionellen Monarchie, cit., pág. 100.

${ }_{121}$ H. Heller, Die politischen Ideenkreise der Gegenwart, cit., pág. 313.

122 Ibidem, pág. 318. 
eminentemente doctrinales. El conflicto entre Estado y sociedad, propio del siglo XIX, encuentra en Alemania un desenvolvimiento eminentemente juridico-teórico. A él pertenecen señaladas construcciones del pensamiento iuspublicista, tales como el concepto de Estado de Derecho y el propio concepto de ley.

Se ha repetido a menudo, y acertadamente, que las formulaciones jurídico-públicas de la doctrina alemana del xix son el reflejo de una clase burguesa socio-económicamente ascendente, pero políticamente estancada. En este sentido, el Estado de Derecho viene a ser «la separación de la estructura política respecto de la organización jurídica, la cual pretende, independientemente de la estructura política, garantizar la libertad y la seguridad» ${ }^{123}$. Ello conduce a la vía jurídico-teórica alemana de abordar el problema de la constitucionalidad del poder político. La debilidad política de la burguesía liberal alemana, frente a la sólida implantación de la monarquía y de la estructura burocrática-autoritaria de la nobleza, obliga a aquélla a desistir de todo intento de plantear la cuestión de la soberanía política, optando entonces por subrogar esta función en la adecuada conceptuación jurídica de la actuación del Estado.

La singularidad del modelo teórico alemán de constitucionalización del poder político no tiene ya tanto que ver con la debilidad real del agente político (burguesía liberal) como con la exigencia que a la reflexión juridicopolítica impone el rechazo del principio de separación de poderes. Es obvia la dificultad que supone la adecuada conceptuación del Estado, cuando no es posible partir de poderes distintos e independientes dentro de él. Ello supone que habrá de ser a través de las categorias jurídico-públicas como habrá de llevarse a cabo la demarcación funcional del Estado. Es decir, no será de los órganos o titulares orgánicos del poder de donde deriven los distintos instrumentos jurídicos de que pueden servirse, sino al revés, será de la tipificación de los distintos instrumentos jurídicos por donde podrá llegarse a la individualización de las formas del poder político.

En consecuencia, la elaboración y conceptuación del Estado de Derecho a lo largo del siglo $\mathrm{xIX}$ se operará sobre la base de la definición de los conceptos de ley y de reglamento, intentando a través de la determinación de sus contenidos y funciones propias, acceder a una clarificación del órgano representativo y de la Corona en el Estado. En ello residirá la «constitucionalización del Estado» en el pensamiento jurídico-público alemán, como señalará GNEIST, en la normalización por ley o «legalización» de los poderes del Estado ${ }^{124}$. Entre los iuspublicistas de la época (Stein, Gneist, Stahl...) esta «legalización» implicaba - a través de la función de

123 Franz L. NeumanN, Die Herschaft des Gesetzes (1. ${ }^{a}$ versión en inglés 1936), Frankfurt 1980, pág. 204.

124 Ver E. W. BOCKENFÖRDE, Gesetz und gesetzgebende Gewalt, Berlín 1969, pág. 163. 
la Corona, que en la monarquía constitucional no sólo detenta el monopolio de Gobierno, sino que también participa constitutivamente en la legislación- una clara primacía del Ejecutivo, como auténtico representante del Estado ${ }^{125}$. Por tanto, en esta primera fase de legalización del Estado en que realmente consiste la construcción doctrinal del Estado de Derecho, se tratará de proponer una definición de ley y de reglamento que, sin atentar a la unidad del Estado, proteja a éste, o a su más claro representante, el Gobierno «frente a las fuerzas de la sociedad que avanzan a través del Legislativo" ${ }^{126}$. Es necesario entonces que, aunque la ley sea la norma superior, no aniquile la autonomía del poder del reglamento. Ello lo consigue esta corriente del pensamiento jurídico mediante el concepto institucional de ley, elaborado por HEGEL ${ }^{127}$. De aquí que, para STEIN, en la construcción del concepto de ley —que, para él, es la voluntad autodeterminante del Estado- habrán de concurrir la representación popular, el Gobierno y el Jefe del Estado (Monarca) ${ }^{128}$. En el marco institucional definido por la ley, la autonomía funcional de la capacidad reglamentaria supone el intento de contrarrestar desde el Estado el avance y penetración del mismo por los intereses sociales ${ }^{129}$.

Responde esta orientación a planteamientos netamente estatalistas. Frente a un orden social del Estado que, para el pensamiento jurídico liberal de este periodo, era algo semejante a una revolución, GNEIST propone, como forma orgánica de relación entre Estado y sociedad, un «orden estatal de la sociedad", en clara tradición hegeliana y coincidiendo con su contemporáneo Stein. Derivación inmediata de esta concepción es la posibilidad de un autónomo poder de Gobierno, únicamente limitado por la fun-

125 Para Stein y Gneist el órgano representativo es sólo el cauce de apropiación del Estado por la sociedad. Ver nota 115. Para Gneist la exigencia de sufragio universal es uel síntoma innegable del desbordamiento del Estado por la sociedad" (Die nationale Rechtsidee von den Stände, Berlin 1894, pág. 269).

126 E. W. BöCKENFÖrde, Gesetz und gesetzgebende Gewalt, cit., pág. 146.

${ }^{127}$ Para Hegel las leyes obtienen su sentido no como medios o instrumentos para alcanzar un fin, sino a partir de la fuerza ordenadora de su razón inmamente. $O$, lo que es lo mismo, lo que caracteriza a la ley, no es el ser una medida instrumental, sino una norma institucional (ver HEGEL, Philosophie de Rechts, § 263). Precisamente por su naturaleza institucional las leyes habrán de ser elaboradas con la participación de todos los sujetos políticos: tanto el elemento estatal (monarca) como el elemento social (la representación estamental), toda vez que la ley supone la fusión e identificación entre Estado y sociedad.

128 L. v. STEIN, Der vollziehende Gewalt, Sttuttgart 1869, vol. I, pág. 78.

${ }_{129}$ Para Stein el principio de sociedad es el principio individualista que, para afirmarse, busca la subordinación y dependencia del otro a los fines propios. Es, pues, el principio generador de desigualdad. La sociedad es "la conciencia de que ésta proporciona al individuo la dependencia de los demás como medio para su realización personal» (L. V. STEIN, Geschichte der sozialen Bewegun, cit., I, página XLI). 
ción reguladora general de la legislatura, pero sin que tal limitación tenga ningún parecido con el dominio normativo que en el constitucionalismo francés ejerce el Legislativo sobre el Ejecutivo ${ }^{130}$. La función reguladora general que ejerce el Legislativo implica la naturaleza institucional que se atribuye a la ley ${ }^{131}$. La ley es el «supremo regulador» ${ }^{132}$ de la voluntad estatal, lo que, sin embargo, no supone reducir la prerrogativa real a la mera función ejecutiva, esto es, a una mera ejecutoria de las disposiciones que contienen las leyes ${ }^{133}$.

Los modelos planteados por STEIN y GNEIST, orientados —dentro de la dialética entre Estado y sociedad - a la fusión de ámbas órdenes en una forma organizativa dirigida por el principio estatal encarnado en el Gobierno, identifican «constitición» con la integración de la sociedad en el Estado según el «orden estatal de la sociedad» o Estado de Derecho ${ }^{134}$. Por consiguiente, la «constitucionalización» del Estado se agota en la realización del principio de legalidad, sin que ni siquiera llegue a plantearse el problema de la relación entre Constitución y legislación. La legislación culmina el ordenamiento estatal. Todo lo que efecte al orden vital y constitucional del Estado, lo que se refiere a las relaciones jurídicas tanto de los individuos entre sí, como entre éstos y el Estado sé incluye en la función legisladora ${ }^{135}$.

El rechazo de la separación de poderes es igualmente para STAHL el fundamento de su idea de Estado de Derecho ${ }^{136}$. No admite el esquema

130 Ver Rudolf GNEIST, Der Rechtsstaat und die Verwaltungsgerichte in Deutschland, (1878), Damstadt 1958, págs. 165-170.

131 Todo lo que reduzca la ley a una manifestación de la voluntad mayoritaria supone, para Gneist, una desnaturalización del concepto de ley (ver R. GNEIST, Der Rechtsstaat und die Verwaltungsgerichte in Deutschland, cit., pág. 167.

132 Ver R. GNEIST, Der Rechtsstaat und..., cit., págs. 18 y 65.

133 Ibidem, pág. 171.

${ }^{134}$ Lo que Gneist denomina un «Gobierno según leyes» (Der Rechtstaat und.., cit., pág. 202).

${ }_{135}$ Ver E. W. BöcKenföde, Gesetz und gesetzgebende Gewalt, cit., pág. 172.

136 Pero en Stahl el rechazo de este principio pasa por el análisis de su auténtico significado. Análisis que supone la más acertada crítica al falseamiento que de la separación de poderes se hizo en el constitucionalismo francés y belga de la época, a fin de poder compatibilizarlo con el -para Stahl más fundamentalprincipio de la unidad de poder del Estado. Para Stahl separación de poderes significa diferencia substancial entre los contenidos que incorpora cada una de las distintas funciones que participan. No se trata, por tanto, de una mera participación de varios sujetos en la actuación de poder del Estado, sino de que "dichos sujetos sean verdaderamente distintos» (J. STAHL, Philosophie des Rechts, vol. II, «Rechtsund Staatslehre», segunda parte, "Die Lehere von Staate un den Prinzipien des deutschen Staatsrechts», $2 .^{a}$ ed., Heildelberg 1846, pág. 177) La separación de poderes no consiste en la participación de varios poderes, sino en el poder de varios titulares, realmente independientes entre sí. 
formal racionalista de la tripartición de funciones, sino que su modelo de constitucionalización del Estado resulta «de la participación en el poder de factores distintos: monarquía, aristocracia, jueces independientes, funcionarios inamovibles, pueblo y opinión pública» ${ }^{137}$. Participación que se sustancia en la ley que, para Stahl, tiene también carácter institucional. Entiende la ley como el ordenamiento perdurable de la condición jurídica de las personas, las que cualifican el status general o particular de las mismas. Los reglamentos son las normas emanadas por el Gobierno, cuyo contenido concreta y colma el status jurídico de las personas definido por la ley.

Dentro del pensamiento clásico sobre el Estado de Derecho; R. MOHL representa, frente a la concepción estatalista de Stahl, Stein y Gneist, la orientación «social». Mohl, que es el creador del concepto de Estado de Derecho, pertenece a la orientación liberal más genuina de la burguesía progresista anterior a marzo de 1848 (lo que los historiadores alemanes denominan Vormärz, es decir, “Pre-Marzo»), que entiende el Estado como un instrumento al servicio de los individuos. Su fin y objeto es garantizar y promover la «existencia individual» ${ }^{138}$, vinculándolo a una exigencia de materialidad del ordenamiento estatal ${ }^{139}$.

El rechazo de la separación de poderes conduce a MOHL a la utilización de las categorias jurídicas de ley y reglamento como auténticos criterios de demarcación política entre el órgano representativo y el Ejecutivo monárquico. El concepto de ley elaborado por Mohl extiende su contenido a todos aquellos mandatos "que afecten de algún modo a los derechos de los individuos, sea ampliándolos, limitándolos o interpretándolos" ${ }^{140}$. Es, por tanto, una auténtica reserva material de ley, de la que el poder reglamentario del Ejecutivo monárquico queda excluido. Además, anticipándose al positivismo jurídico y su doble concepto de ley, Mohl establece que «cualquier otro contenido, susceptible de ser válidamente regulado por disposición gubernativa, está disponible para que el rey y los estamentos lo fijen tanto más firme e inalterablemente por medio de ley" ${ }^{141}$. Lo que abre la vía a la expansión competencial de la representación popular respecto al Ejecutivo monárquico. El sistema juridico-público de Mohl es un claro ejemplo de que la teoría general del Estado de Derecho se orienta exclusivamente a la limitación del poder Ejecutivo del monarca. Ello se percibe con más claridad aún en la exposición que hace del derecho

137 Ver J. STAHL, op. cit, pág. 178.

${ }^{128}$ Ver E. W. BOCKENFÖRDE, Gesetz und gesetzgebende Gewalt, cit., pág. 179.

139 Heller considera la noción de Estado de Derecho de Mohl una afortunada sintesis de seguridad jurídico-formal y justicia material. Síntesis que desaparecerá en el proceso formalizador posterior (ver H. HELLER, "Rechtsstaat oder Diktatur?" 1929, en Gesammelte Schriften, Leiden 1971, vol. II, pág. 449.

140 Robert von MoHL, Das Staatsrecht des Königsreichs Würtemberge, segunda edición, Tübingen 1840, vol. l, pág. 67.

141 Ibidem, pág. 67. 
reglamentario ${ }^{142}$, cuya subordinación formal y material a la legislación es tan intensa, que los reglamentos quedan reducidos a la mera ejecutoria de las leyes.

La confianza en la legislación es en Mohl plena. El imperio de la ley no se ve empañado aquí ni siquiera por el superior rango que Mohl concede a la Constitución. La constitucionalidad culmina también en Mohl en el principio de legalidad del Estado. La tan comentada «juridificación de la política» en Mohl se orienta exclusivamente al Ejecutivo ${ }^{143}$. Las garantías judiciales de la Constitución, residenciadas en una Corte de Estado (Staatsgerichtshof), conforman, en realidad, una jurisdicción contencioso-administrativa de nivel politico, ya que dicho tribunal actúa como instancia arbitral en los conflictos entre órganos del Estado ${ }^{144}$. Por tanto, la clara y precisa distinción entre rango normativo de la Constitución y el del resto del ordenamiento, este doble nivel de legalidad carece sin embargo en

142 Para Mohl el derecho reglamentario incluye normas que no generan derecho nuevo, que no pueden añadir nada nuevo a los derechos de los ciudadanos, sino que han de limitarse a ordenar y regular lo que se encuentra determinado por las leyes.

${ }_{143}$ Como expone acertadamente Ingeborg Maus, «Entwicklung und Funktionswandel der Theorie des bürgerlichen Rechtsstaates", en M. TOHIDIPUR (Ed.) Der bürgerliche Rechtsstaat, Frankfurt 1978, vol. I, pág. 24 ss., pág. 70, notas 70 y 71.

${ }_{144}$ Esta jurisdicción, tal y como la desarrolla Mohl, podria incluirse, como mucho, dentro del concepto de Staatsgerichtsbarkeit, entendida como una «jurisdicción estatal', orientada a la resolución de conflictos entre órganos políticos. Sería una especie de jurisdicción contenciosa del máximo nivel. No hay en Mohl referencia alguna al control judicial de las leyes, que es el rasgo esencial y diferenciador de una auténtica jurisdicción constitucional. Cierto que Mohl extiende las competencias de la "Corte de Estado" sobre aquellas actuaciones «encaminadas a derrocar la Constitución», así como también sobre las "violaciones puntuales de la Constitución” (R. v. MoHL, Das Staatsrecht..., cit., I, pág. 767). También contemplará como competencias de la Corte de Estado el control y sanción de los «intentos de anular por procedimientos indebidos la Constitución en tanto que ley vigente». Respecto de cuales sean los procedimientos indebidos, es algo que Mohl no precisa. Ciertamente Mohl prevé la superioridad de la Constitución frente a las leyes: "Todas las leyes y reglamentos anteriores, independientemente de su significación jurídico-política, que contradigan una determinación expresa de la Constitución, son nulas» (R. v. MoHL, op. cit., I, págs. 90-91). Asimismo, «la Constitución es superior y prevalente respecto de las leyes y reglamentos emanados después de su promulgación. En este caso de una contradicción mediata o inmediata, será nula no la correspondiente determinación de la ley fundamental, sino más bien la de la ley o reglamento, aunque estas últimas sean las normas posteriores" (R. v. MoHL, Das Staatsrecht...; cit., I, pág. 91). Pero no contempla procedimiento alguno para hacer efectiva la superioridad de la Constitución. Por otro lado, aquella parte de la Constitución consistente en los derechos y libertades de los súbditos frente al Gobierno, encuentran su expresión y defensa, precisamente a través de la Asamblea representativa (ver R. v. MoHL, Das Staatsrecht..., cit., I, pág. 67). De donde se deduce que es el Legislativo el órgano encargado de la defensa de la Constitución. 
Mohl de expresión institucional. Su concepción no recoge el derecho de revisión judicial de las leyes, sino que como única vía de actuación frente a las leyes injustas recomienda la desobediencia civil del ciudadano. Para Mohl la ley inconstitucional es, ante todo, una ley injusta y, por tanto, nula en sí misma, sin que ello requiera «una declaración específica o una retirada expresa, sino que el ciudadano se encuentra facultado para negarle simplemente la obediencia» ${ }^{145}$. Es una concepción que responde al criterio de imperio de la ley. La Asamblea representativa es considerada como depositaria de los intereses de la sociedad frente al Gobierno y a la Administración, inaugurándose así el marco teórico que contempla a los elementos de la integración Estado-sociedad (monarca y parlamento) como agentes políticos y confiriendo - a diferencia de las ópticas estatalistas de Stein y Gneist - la preeminencia y dirección del proceso integrador al legislador.

En todos los juristas hasta ahora referidos, independientemente de su orientación estatalista (Stein, Gneist), de su inclinación por el «principio monárquico" (stahl) o de su carácter "social" (Mohl), rige el criterio de subrogar en la determinación de las categorías juridicas (ley-reglamento), el problema de la delimitación y subordinación «politica» de los poderes del Estado ${ }^{146}$. Lo cual quiere decir que la jerarquía normativa se efectuará, no atendiendo al rango de los órganos que emanan las normas, sino en función de la determinación material del contenido de las mismas. De aquí la significación que corresponde a la definición material de los conceptos de ley y reglamento en la construcción del Estado de Derecho. Fue este planteamiento el que congeló la constitucionalización del sistema político alemán del xIx al nivel del principio de legalidad. El código político de la burguesia liberal se centraba en el control jurídico del Ejecutivo o, lo que es lo mismo, garantias jurídicas «frente a intervenciones arbitrarias del absolutismo en la esfera de la libertad y la propiedad individuales. Del Estado hay que exigir, por tanto, seguridad entendida como "certeza de la libertad legal"'" ${ }^{147}$. A esta exigencia responde, en última instancia, el propio

145 Lo que viene a ser congruente con la función que Mohl atribuye al Parlamento, como defensor de los derechos y libertades fundamentales (ver nota anterior). De este modo, frente a un Parlamento injusto al ciudadano sólo le queda la desobediencia (ver R. v. MoHL, Das Staatsrecht..., cit., I, págs. 91-92).

146 Ello responde - ver nota 116- a una repulsa general de la separación de poderes. Además, la desconfianza ante la instrumentalización del Estado por los intereses necesariamente parciales de la sociedad en Stein y Gneist, propicia un apoyo a la preeminencia del Ejecutivo monárquico en el proceso constitucionalizador del Estado. Pero también es cierto, que la debilidad política de la burguesía liberal tampoco estaba en condiciones de imponer, no ya la parlamentarización del sistema político (algo que, en Alemania no se conseguirá hasta 1919), sino tampoco la preeminencia del Legislativo a través de una confrontación política con el Gobierno.

147 H. Heller, Die politischen Ideenkreise..., cit., pág. 337. 
concepto de Estado de Derecho, que puede ser definido como la forma regulada de actuación del poder como garantía de los derechos adquiridos de los ciudadanos ${ }^{148}$. Por ello definirá O. MEYER el Estado de Derecho como el «Estado de derecho administrativo bien ordenado» ${ }^{149}$.

Se pretende conferir al Derecho la función de fijar los ámbitos de poder, las competencias, pero sin que ninguna instancia política tenga atribuida la competencia de la competencia. Aunque la soberanía se considera residenciada en el monarca ${ }^{150}$, este atributo irá convirtiéndose en un reconocimiento formal ${ }^{15 t}$, no en favor del Parlamento, sino en favor de la soberanía del derecho. Aquí reside precisamente la vía política subrogada que asumen las categorias jurídicas en la idea de Estado de Derecho. Consiste en la fijación por medio del derecho de las competencias del Estado ${ }^{152}$, impidiendo que el ejecutivo monárquico pueda alterarlo atribuyéndole una función reguladora no susceptible de crear, modificar o derogar derecho. Pero el derecho (su creación, alteración o derogación) tampoco queda a disposición del órgano representativo, sino en el poder Legislativo, el cual incluye, en la monarquía constitucional, las Cámaras y el rey. Sólo así es posible garantizar una verdadera soberania del derecho ${ }^{153}$. Cuando el

${ }_{148}$ Ver L. V. STEIN, «Rechtsstaat und Verwaltungsrechtspflege», en Grünhuts Zeitschrift für das private und öffentliche Recht, 1879, vol. I, pág. 58 .

149 Otto MeVER, Deutsches Verwaltungsrecht, München-Leipzig 1895, 3. ed. 1924, vol. I, pág. 58.

150 Como señala Mohl, «El postulado general es que en la monarquia con representación popular pertenece al rey la totalidad del poder estatal y su ejercicio en los casos individualizados" (Das Staatsrecht..., cit., I, pág. 533).

${ }_{151}$ Pero la cuestión de la soberanía se encuentra, por lo que atañe al concepto de Estado de Derecho, encuadrada en el planteamiento hegeliano respecto de la individualidad y unidad del Estado. Aplicando entonces al concepto de Estado de Derecho la conclusión de Franz Resenzweig sobre Hegel, podemos decir que en la noción de Estado de Derecho el monarca no es soberano, ello sólo lo es el Estado, pero la soberanía sí es monárquica.

152 Esta exigencia la satisface como ninguna otra la definición de Stahl; en ello están de acuerdo hasta sus más apasionados detractores. Para Stahl, «el Estado en el que se encuentra la solución y a donde tiende en verdad el impulso evolutivo de los nuevos tiempos es el Estado de Derecho. Él es el que establece exacta e inquebrantablemente en derecho los cauces y límites de su actuación y la esfera de libertad de los ciudadanos. Todo ello sin imponer de modo directo, imperativamente, la idea moral más alla de lo que corresponde en derecho, es decir, sólo en la medida imprescindible. Por tanto, el Estado de Derecho no consiste en la mera utilización por el Estado del ordenamiento jurídico sin fines administrativos, ni tampoco en la plena protección de los derechos individuales. Estado de Derecho no significa el fin o el contenido del Estado, sino únicamente la forma y el carácter de su realización» (F. J. StaHL, Philosophie des Rechts, cit., vol. II, pág. 137).

${ }_{153}$ Es evidente que la idea de soberanía del derecho es únicamente posible en la medida en que la fuerza normativa del derecho se independice respecto de la voluntad de los poderes del Estado individualmente considerados. Lo cual es 
carácter institucional de la ley — considerada como única fuente de derecho- hace de ella un instrumento normativo no disponible por ninguno de los factores del Estado, sino por la concurrencia y participación de todos ellos. Es evidente que una construcción jurídico-política de esta indole rechaza implícitamente la idea de supremacia jurídica de la Constitución, ya que en la idea clásica de Estado de Derecho (Stein, Mohl, Stahl, Gneist) el legislador es el propio Estado y, por ello, su voluntad es ilimitable.

La controversia y la dialéctica entre los distintos agentes o factores jurídico-políticos que trasluce la polémica doctrinal en torno a la definición de ley y reglamento, viene a expresar la autonomización de la Asamblea representativa respecto de la participación de la Corona en la función legislativa, que se transforma en un gesto cada vez más formal. Es un proceso que se complementa con el retraimiento del monarca a la función del Gobierno, identificándose la prerrogativa real con la función reglamentaria. Ello supone el desmontaje del «legislador institucional», en cuyo contexto ha de entenderse la contraposición entre ley y reglamento, en tanto que formas normativas que subrogan - a través de la distinta dimensión de su reserva material - una pretensión jerarquizadora del Ejecutivo monárquico respecto de las Cámaras.

Esta transformación interna en la estructura conceptual e institucional del Estado de Derecho clásico se acentúa con la formalización de las categorías jurídicas que acompaña a la implantación del positivismo juridico. Orientación que responde a la pretensión de reducir el derecho $-\mathrm{y}$, en especial, el derecho público-a criterios estrictamente jurídico-técnicos de argumentación. Iniciada con la obra de C. F. v. Gerber, la ciencia jurídica deviene, para esta escuela, susceptible de una construcción dogmática y objetiva, quedando el derecho «desvinculado de connotaciones sociales y sentido teleológico. El fin, la función y los condicionamientos de los institutos jurídicos están situados más allá de su concepto" ${ }^{154}$. El contenido de

únicamente realizable si en la creación del derecho concurren todos ellos, confiriendo después, a cada uno de dichos poderes por separado, una potestad normativa que necesariamente habrá de ser intra legem. Evidentemente que, en este contexto, la soberanía de derecho no sólo no tiene nada que ver con la soberanía del Parlamente, sino que es, quizá, su más directa contraposición. Soberanía del Parlamento no significa en absoluto soberanía del derecho, sino la capacidad de aquel poder cuya soberania le permite disponer del derecho. De aquí que la crítica que el pensamiento jurídico-político actual suele hacer a la teoría del Estado de Derecho, en el sentido de que representa el intento de afirmar la soberanía del derecho sin que la burguesía dispusiese de la soberanía del Parlamento (v. I. Maus, op. cit., pág. 19), es sólo una simplificación del significado jurídico-político del concepto de Estado de Derecho. Por el contrario, hay que decir que la idea de soberanía del Parlamento es completamente extraña y ajena al concepto de Estado de Derecho (v. Martin Kriele, Einführung in die Staatslehre, Reinbek, 1975; F. GARZoNI, op. cit.).

${ }^{154}$ E. W. BöKENFÖRDE, Gesetz und..., cit., pág. 212. 
la ciencia jurídica lo constituyen exclusivamente las leyes positivas ${ }^{155}$. Determinante para la reflexión jurídica de esta escuela es la filiación iusprivatista de su más conspicuos representantes (Gerber y Laband), lo que hace que el fundamento de sus construcciones juridico-públicas remitan a la parte general de Los Pandectas. Se produce entonces una extensión al derecho público de los conceptos acuñados y elaborados por el derecho privado, con lo que, como comenta BÖCKENFÖRDE «el concepto jurídicocivil de persona jurídica se transfiere a la personalidad del Estado, el de lex al de ley en sentido jurídico-político, el de actio al de derecho público subjetivo» ${ }^{156}$.

Comienza con el positivismo jurídico un proceso de total juridificación del derecho político, intensificándose la óptica jurídica, en la ya de por si juridificada cuestión del concepto de Estado. La acentuación del proceso juridificador puede entenderse como reacción de la burguesía liberal alemana al fracaso del movimiento constitucionalista de 1848. La imposibilidad de alcanzar la plena constitucionalización de la Corona - lo que sólo se hubiera conseguido por vía «revolucionaria»o, en otras palabras, por una vía de actuación "política», capaz de trascender el orden jurídico-político existente, instituido como estaba sobre el "principio monárquico», obliga al pensamiento liberal a efectuar un diseño del ordenamiento que instaure de iure la supremacía estatal del Legislativo sobre la Administración y el Gobierno. El compromiso entre las exigencias del movimiento constitucionalista liberal y las posiciones de los poderes históricamente asentados (Corona, funcionariado, aristocracia, ejército) con que se salda el movimiento de 1848, se sustanció en la Constitución prusiana de 1850. Aunque es una Constitución fundamentada en el «principio monárquico»-esto es, una Constitución en la que el poder real no emana de la Constitución, sino que se considera anterior a ella y al que la Constitución únicamente limita-, no obstante no niega totalmente la separación de poderes.

Fue en torno a la interpretación del artículo 62 de la Constitución de 1850 , en el que se define la competencia legislativa ${ }^{157}$, donde la doctri-

155 No repetiremos aquí la crítica que, desde $\mathrm{O}$. Gierke hasta la actualidad se ha efectuado al positivismo jurídico -entendido como una estricta orientación metodológica - y su intensificación en el positivismo normativo- caracterizado como aquella concepción jurídica que identifica ley y derecho- (v. Franz WIEACKER, Privatrechtsgeschichte der Neuzeit, Göttingen 1952). Sólo señalaremos aquí la amplia crítica que suscitó esta escuela, en sus orígenes, por Gierke y, posteriormente, en Heller, y entre nosotros la desarrollada por Lucas Verdú.

156 E. W. BOCKENFORDE, Gesetz und..., cit., pág. 218.

157 El artículo 62 establecía en su comienzo: «El Poder Legislativo se ejerce conjuntamente por el rey y las Cámaras. Para cada ley es necesario la conformidad del rey y de ambas Cámaras...». En la interpretación de este precepto Laband argumentó que la primera frase del artículo 62 entiende el Poder Legislativo en sentido material, mientras que la segunda entiende la ley en sentido formal. Sólo así era 
na alemana elabora el concepto dual de ley. Para ello se procede a una definición de la materialidad de la ley, independientemente de sus distintivos formales, cuya determinación no ofrece dificultad alguna. Por el contrario, los contenidos necesarios o propios de la ley, no resulta algo evidente en sí mismo. La definición de la materialidad de la ley que conseguirá la mayor aceptación en la evolución del Estado de Derecho, es la que se afianza a lo largo de las concepciones de P. Laband. G. Jallinek y G. Anschütz. Se inicia en LABAND la idea de que ley en sentido material es aquella norma cuyo contenido es un "enunciado de derecho" ${ }^{158} 0$, más exactamente, un enunciado creador de derecho.

La distinción entre ley en sentido formal y ley en sentido material permitirá, en todo caso, una gran expansión funcional y competencial del Legislativo. Por un lado, la generosa definición del concepto material de ley permite extender correspondientemente la reserva de ley formal. Por otro lado, el hecho de que el concepto formal de ley no se encontrase expresamente reservado a las materias propias de la ley permitía la expansión ilimitada de la legislación, ya que al conferir forma de ley a cualquier contenido o materia, por efecto de la congelación del rango, queda automáticamente substraído a la competencia reglamentaria. La expansión legislativa que así se produce no se le oculta a Laband, para quien «allí donde se pretendiese excluir la decisión autónoma del monarca o de sus ministros, se exigiría una ley, es decir, la observancia del procedimiento formal previsto para la legislación, procedimiento en el que se incluye la aprobación por la representación popular" ${ }^{159}$. Con ello el concepto formal de ley se independiza de su correspondiente contenido material, invirtiéndose los términos hasta entonces existentes entre materialidad y formalidad de la ley, que hacía de esta última el apéndice de la primera. Era la forma normativa obligada para determinados contenidos. Sin embargo, en Laband, la ley en sentido formal pasa a ser el momento fundamentador del concepto de ley, al tiempo que la ley en sentido material aparece sólo como un contenido posible de lo que ha venido a ser la idea general de ley: la ley formal ${ }^{160}$

posible, según Laband, evitar que todo el precepto cayese en una mera tautología. (v. E. W. BöcKENFÖRDE, op. cit., pág. 222).

158 Para Laband el «enunciado de derecho» ha de cumplir la función de «determinar los límites y barreras de la natural libertad de acción de los individuos. Límites exigidos por la existencia comunitaria del hombre" (Paul LABAND, Das Staatsrecht des deutschen Reiches, $4{ }^{2}{ }^{2}$ edición, vol. II, pág. 67).

159 Ibidem, pág. 561.

160 Ello encuentra su más clara expresión en el célebre texto de Laband: «En una palabra, no hay ni un solo objeto de la vida estatal; más aún, puede afirmarse que no existe idea alguna que no pudiera convertirse en el contenido de una ley» (Das Staatsrecht..., cit., II, pág. 57). 
Respecto a la formulación de las categorías jurídicas, cuya máxima expresión es el sistema de Laband, ha suscitado criticas que han devenido, a su vez, clásicas ${ }^{161}$. Sabido es la indefensión que dicha formalización ocasiona a los sistemas políticos: el abandono de criterios suprapositivos en la creación e interpretación del derecho, supone el sometimiento a la autoridad exclusivamente voluntarista de la ley -ya que el concepto formal de ley coincide con la voluntad imperativa- en un contexto en el que el infradesarrollo de la idea de Constitución, concentra todo el poder en el órgano legislativo. El imperio de la ley, la mera legalidad adquiere dimensión constitucional y el Estado de Derecho se reduce al Estado de derecho administrativo ${ }^{162}$. El objetivo iusracionalista de un orden general según los principios de la razón, a lo que la idea institucional de ley de la concepción clásica del Estado de Derecho pretendía dar respuesta, queda reducido al mero control legal del poder Ejecutivo. Para O. MEYER «lo que así queda limitado es únicamente la Corona, el poder Ejecutivo (...). Los aspectos más importantes y sensibles del hombre y el ciudadano frente al poder del Estado quedan bajo la protección de la ley y, por tanto, de la Asamblea Nacional (...). La ley lo puede todo; todos los derechos de libertad pueden ser limitados por la ley» ${ }^{163}$.

Interesa resaltar en qué medida la tendencia formalizadora del positivismo produce, a nivel institucional, la omnipotencia del órgano legislativo. Omnipotencia que no suscita sospecha o escepticismo alguno debido a que «la burguesía dispone de una influencia considerable en el proceso legislativo" ${ }^{164}$. En la misma medida en que, durante la segunda mitad del XIX, el órgano representativo amplía su ámbito de influencia -expansión institucional que acompaña a la implantación del positivismo y formalismo juridico - es cuando ya puede aparecer de manera explícita como garante institucional de los intereses de la burguesía. Este paso se opera en la definición material de la ley propugnada por $G$. Anschütz en función de la cláusula de libertad y propiedad. A la ley corresponderá necesariamente -independientemente de los contenidos que puedan incluirse debido a la preeminencia del concepto formal de ley - toda materia que afecte a la libertad y a la propiedad de los individuos ${ }^{165}$.

161 Ver nota 155.

162 O. MeYer (ver nota 149). G. Anschütz definirá el Estado de Derecho de esta época como un cdeterminado orden relacional entre ley, Administración e individuo", de tal modo que "la Administración no podrá incidir en la esfera de libertad del individuo ni por medio de una disposición contra legem, ni por medio de una sin fundamentación legal (praeter o ultra legem)" (Gerhard ANSCHÜTZ, en MEYERANSchütz, Lehrbuch des deutschen Staatsrechts, 7. edición, 1919, pág. 29, nota b).

163 O. MEYER, op. cit., vol. I, pág. 70, nota 12.

164 F. L. Neumann, op. cit., pág. 229.

${ }_{165}$ Tesis que, si bien fuera formulada primero por Max $V$. Seydel en la primera edición de su Bayerisches Staatsrecht (1884), su principal defensor fue G. Anschütz desde el año 1898. 
La evolución formalizadora de la idea de Estado de Derecho, hasta la omnipotencia legislativa del positivismo jurídico, unido al déficit democrático del órgano representativo y a la identidad sociológica entre el Parlamento y la clase económica dominante, hace innecesario el recurso a un estatuto jurídico supremo (Constitución) limitador de las actuaciones del legislador. Las leyes son intervenciones del Estado en la libertad y propiedad de los ciudadanos, pero siendo la ley un monopolio del Parlamento «cuando éste se encuentra ocupado por la burguesía, entonces la doctrina del imperio de la ley significa que la clase social en la que tienen lugar las intervenciones, interviene sobre sí misma. En este contexto se comprende que esta clase social atienda a sus propios intereses» ${ }^{166}$. La atribución explícita de la competencia reguladora sobre todo lo que afecte a la libertad y a la propiedad, viene a ser el amparo institucional de los intereses socioeconómicos dominantes frente a eventuales intervenciones por parte del Ejecutivo monárquico, sin que en ningún momento se plantee la necesidad de un control de la función legislativa. El concepto de Estado de Derecho se define ahora en torno al «ilimitado poder Legislativo», competente para regular «más allá de toda libertad, derechos, privilegios y situaciones consolidadas", sin sometimiento a forma ninguna de supralegalidad, ya que la idea de «Estado de Derecho queda abandonada en la misma medida en que se pretende someter al Estado a un derecho absoluto, independiente del poder normativo del hombre» ${ }^{167}$.

En este sentido la relación entre el factor institucional (monopolio de la ley y el derecho por el Legislativo), del doctrinal (concepto de Estado de Derecho centrado en el principio de legalidad) y del socio-político (sufragio censitario e identidad sociológica entre clase económica y clase política) hacen superfluo plantear la necesidad de una jurisdicción constitucional entendida como revisión judicial de las leyes ${ }^{168}$. Sin embargo, el peso específico que en este encadenamiento corresponde al déficit democrático de la representación política, hace de él el factor determinante para la existencia o no de aquella jurisdicción. Esto se evidencia, precisamente, en el cambio de las concepciones generales sobre el Estado de Derecho operado en la doctrina jurídico-política alemana, a raíz de la introducción del sufragio universal con la aprobación de la Constitución de Weimar en 1919.

166 F. L. Neumann, op. cit., pág. 299.

167 Ambas citas corresponden a Richard THомA, «Rechtsstaatsidee und Verwaltungsrechtswissenschaft», en Jahrbuch für öffentliches Recht, n. ${ }^{\circ}$, 1910, páginas 196-97.

${ }_{168}$ Son reveladoras a estos efectos las palabras de Bluntschli referentes a lo innecesario de una revisión judicial de las leyes, debido a que cel órgano Legislativo lleva en su composición las máximas garantías de que no ejercerá sus facultades con ánimo inconstitucional» (J. C. BLUNTSCHLI, Allgemeines Staatsrecht (1876), 5. ${ }^{2}$ edición. Stuttgart, pág. 138). 
Este simple y trascendental acontecimiento, el sufragio universal, desencadena un proceso de redefinición de las distintas posiciones doctrinales. La democratización de la representación política supone la pérdida por parte de la clase económica dominante del monopolio Legislativo. El Parlamento, ahora órgano de integración social, puede caer bajo el dominio de los intereses obreros mayoritarios, surgiendo la posibilidad de colisión entre las decisiones legislativas y las estructuras consolidadas de poder económico. Ante la eventualidad de que un Legislativo democráticamente legitimado propenda a actuaciones redistributivas de la propiedad y la riqueza, es cuando se plantea la necesidad de alguna forma de control objetivo de la voluntad del legislador. No tiene nada de extraño entonces que en esta situación se replantee - por significados representantes del positivismo jurídico, partidarios anteriormente de la omnipotencia del Legislativo - la necesidad de un orden supralegal vinculante para el legislador. A este respecto resulta sintomático el caso del propio R. THOMA, defensor todavia en 1910 de un ilimitado poder Legislativo ${ }^{169}$ como condición inherente al concepto de Estado de Derecho, plantear durante la República de Weimar la necesidad de "claras reglas generales y amplias garantías de la adecuación a derecho de la actuación del Estado ${ }^{170}$. La exigencia, por tanto, de criterios objetivos de derecho a los que someter la actuación del Legislativo ${ }^{171}$.

La orientación formalista del positivismo jurídico, que había defendido hasta entonces el imperio de la ley $-y$, por ende, del legisladorcomo máximo exponente del orden constitucional, reivindica ahora, frente a un legislador eventualmente «revolucionario» o «reformador», la substancialidad del derecho frente a la ley como límite a la voluntad de la legislatura. La reacción doctrinal conservadora se operó en dos frentes. Por un lado, recuperando postulados iusnaturalistas en los que fundamentar la diferencia entre ley y derecho. Por otro, se apela a un control judicial de la doble legalidad (derecho y ley) directamente orientado al control de constitucionalidad de las leyes.

Exponente de la primera orientación es el neoiusnaturalismo, que propugna sustantivar una esfera normativa suprapositiva, vinculante para

169 Ver nota 167.

170 Richard ThOMA, «Der Vorbehalt der Legislative uns das Prinzip der Gesetzmässigkeit von Verwaltung und Rechtssprchung", en G. ANSCHÜTZ/R. THOMA (editores), Handbuch des deutschen Staatsrechts», Tübingen, 1932, vol. II, pág. 221.

171 Se produjo una redefinición de las posiciones doctrinales en el campo del derecho. El resultado fue que numerosos representantes de orientación conservadora (formalismo jurídico) se orientaron hacia posiciones doctrinales antiformalistas (R. Thoma, C. Schmitt...) y consecuentemente numerosos teóricos socialistas (que anteriormente habian mantenido tesis sustancialistas y de materialidad del derecho) se inclinaron hacia el positivismo jurídico (E. Fraenkel, F. L. Neumann, Gustav Radbruch; ver I. Maus, op. cit., pág. 39 y ss). 
el legislador, pero no disponible a su voluntad. Para KAUFMANN, el más señalado representante del neoiusnaturalismo, el «Estado no crea derecho; el Estado crea leyes y las leyes y el Estado se hayan sometidos a derecho" ${ }^{172}$. Se trata de postulados de orden axiológico-juridico (justicia, igualdad, generalidad...) que, para el neoiusnaturalismo, integran el orden sustantivo del derecho y que el pensamiento conservador entenderá como exigencias dirigidas al legislador. Kaufmann insistirá en que el principio de igualdad no es ya, como en el contexto doctrinal del liberalismo del siglo anterior, una imposición exclusivamente dirigida a la Administración y a los tribunales, sino una exigencia «dirigida ante todo y en primer lugar al legislador, que es el encargado de emanar derecho escrito, pero sin que pueda vulnerar este principio del derecho" ${ }^{173}$. Similar en sus planteamientos será la recuperación emprendida por SCHMITT del principio de igualdad ${ }^{174}$. El postulado de generalidad como atributo inherente a todo contenido de la ley se orienta - como sucede con la exigencia de la igualdad de la ley- a impedir el tratamiento diferenciado para situaciones sociales desiguales. Se pretende, por medio de esta supralegalidad vinculante para el legislador, sustituir la anterior limitación normativa, derivada de la composición sociológica del órgano, por la que resulta de los imperativos de generalidad e igualdad de la ley, en la medida en que impiden la expresión normativa de intereses sociales parciales y, con ello, la incidencia configuradora del Legislativo en el substrato económico de la desigualdad social. Se impide, en suma, la posibilidad de entender la ley como instrumento productor de igualdad.

La supraordenación del derecho frente a la ley del pensamiento conservador, proporcionó el fundamento para la sustantivación de la propia Constitución y, a través de ello, la articulación de una doble legalidad (leyConstitución) que ve en los jueces el instrumento para dotar de efectividad a la limitación constitucional del legislador ${ }^{175}$.

Frente a ambas orientaciones persiste la que sostiene la validez de los principios del Estado de Derecho de la época anterior: imperio de la ley como expresión de la omnipotencia legislativa, susceptible de articular normativamente los programas reformistas de los partidos politicos po-

172 Erich KaUfMANN, «Die Gleichheit vor dem Gesetz im Sinne des art. 109», en Neröffentlichungen des Vereins des Deutschen Staatsrechtslehrer, n. ${ }^{\circ}$, pág. 20.

173 E. Kaufmann, op. cit., págs. 5-6.

174 «Ley no es la voluntad de uno o varios hombres, sino algo racional general. No es voluntas sino ratio" (Carl Sснмітт, Verfassungslehre (1928), reimpresión, Berlín 1970, pág. 139).

175 I. Maus, op. cit., pág. 40. 
pulares, claramente mayoritarios ${ }^{176}$. A ello se referirá ANSCHÜTZ, al reclamar la plena disponibilidad de la ley por el legislador, ya que la «idea de un especifico poder constituyente, distinto del poder Legislativo y supraordenado a él es, en contraposición a Norteamérica, completamente extraño al derecho político alemán. La Constitución no se encuentra por encima del Legislativo, sino a disposición del mismo», lo que implica «un hecho que, entre otras cuestiones, es de una importancia fundamental para el derecho de revisión judicial»" ${ }^{177}$. Posición doctrinal que respondía al espíritu de la propia Constitución de 1919, cuya cláusula de reforma (art. 76) establecia una rigidez mínima, ya que la Constitución era reformable por ley cualificada (2/3). Obviamente, la escasa resistencia que la Constitución podía ofrecer a la ley, difícilmente justificaba su pretensión de supremacia.

El control de constitucionalidad de las leyes se introdujo en el sistema constitutucional de la República de Weimar gracias a la presión doctrinal de los sectores conservadores del derecho, entre los que no ocupaban un último lugar los propios jueces. $Y$ se introdujo por razones de clara oportunidad política, ante la amenaza de un poder Legislativo susceptible de operar una «revolución legal».

La cuestión de la jurisdicción constitucional tuvo un desarrollo harto contradictorio durante la República de Weimar. Empezando porque la propia Constitución no preveía una verdadera jurisdicción constitucional. En sus artículos 13.2 y 19.1 contempla la posibilidad de conflictos entre las instituciones políticas de un Estado federal [conflictos constitucionales dentro de un mismo Estado federado, conflictos entre distintos Estados federados o entre uno de éstos y la Federación (art. 19.1)], así como los conflictos derivados de la diversidad de opiniones sobre compatibilidad entre disposiciones estatales y el derecho federal (art. 13.2). Conflictos cuya solución se encomendaba a distintintas instancias judiciales: las del artículo 19.1 a una Corte de Estado, las del artículo 13.2 a la correspondiente sala del Tribunal Supremo. En sentido estricto se trataba de una jurisdicción estatal propia de un Estado federal. Es decir, se trataba de una jurisdicción administrativa de nivel político ${ }^{178}$ (una Staatsgerichtsbarkeit), pero no de

176 Es el modelo de Estado que Schmitt descalificaria con el término de «Estado legislador", y que es sólo una fase introductoria a lo que tambien Schmitt calificaría como "Estado partisano", en el que la burguesía conservadora cree percibir «el típico vehículo de una era reformista-revisionista-evolucionista armado de programas de partido, que busca realizar el "progreso" por la vía parlamentaria legal» (Carl Schмiтt, Der Begriff des Politischen (1932), Berlín 1963, pág. 16).

177 G. Anschütz, Die Verfassung des deutschen Reiches, 4. 'edición, 1926, artículo 76, pág. 229.

${ }_{178}$ Como expone Walter Simons - presidente de la Corte de Estado y del Tribunal Supremo durante el primer periodo de la República de Weimar- en la introducción al primer volumen de la jurisprudencia de ambos tribunales, este nuevo tipo de jurisdicción pública se centra en las «relaciones entre las corporaciones 
una verdadera jurisdicción constitucional (Verfassungsgerichtsbarkeit) ${ }^{179}$, cuyo núcleo fundamentador es, precisamente, aquella competencia que la Constitución de Weimar no recoge: el control de constitucionalidad de las leyes federales ${ }^{180}$.

Los debates constituyentes demuestran que la ausencia de mecanismos de control de constitucionalidad de las leyes no fue casual. Fueron propuestos varios modelos para dar cauce a esta institución ${ }^{181}$. Posteriormente, a lo largo de la República de Weimar, la discusión entre partidarios (Preuss, Triepel...) y contrarios (Anschütz, Heller...) a la introducción de una jurisdiccion constitucional pasó a segundo plano. La discusión pasó a centrarse en los modelos posibles. Entre los partidarios de una capacidad judicial general de revisión (judicial review americano), y los que optan por la concentración de esta capacidad en un órgano ad hoc. Por su lado, las leyes que se emanaron para dar cumplimiento a las competencias decisorias que la Constitución atribuía al Tribunal Supremo (art. 13.2) y a la Corte de Estado (art. 19.1), concretamente la Ley de 8 abril de 1920 respecto a la actuación del Tribunal Supremo y la Ley de 9 de julio de 1921 sobre la Corte de Estado, tampoco ayudaron a clarificar la situación. A ello vino a sumarse la célebre sentencia del Tribunal Supremo de 4 de noviembre de 1925 por la que se introducía la revisión de las leyes federales respecto de su constitucionalidad por los órganos judiciales ${ }^{182}$. Culmina

políticas de la Federación», lamentándose a continuación de que sea generalmente confundida con una jurisdicción contenciosa más (W. SIMONS, «Geleitwort zum ersten Band von: Die Rechtssprechung des Staatsgerichtshofs für das deutsche Reich und des Reichsgerichts», en P. HÄBERLE (ed.) Verfassungsgerichtsbarkeit, Darmtadt 1976, pág. 133).

179 R. Grau distingue ya en 1926 entre una "Corte de Estado" (Staatsgerichtshof) encargada de distribuir con independencia judicial responsabilidades y atribuciones entre los órganos políticos, y un Tribunal Constitucional (Verfassungsgerichtsbarkeit) que habrá de decidir cuestiones de derecho constitucional como un fideicomisario de la Constitución (cit, en C. ScHмITT, Verfassungslehre, cit., pág. 118).

${ }_{180}$ Como dirá SCHMITT, "Una jurisdicción general o justicia constitucional no existe hasta la fecha» («Das Reichsgericht als Hüter der Verfassung», en Verfassungsrechtliche Abhandlungen, Berlín 1973, pág. 73).

181 El Dr. Ablass propuso que la Corte de Estado pudiese decidir vinculantemente a iniciativa de 100 diputados sobre la constitucionalidad de las leyes (la propuesta fue rechazada). Otros miembros de la Asamblea constituyente (Hugo Preuss, Morstein Marx) pidieron un derecho general de revisión judicial, que deberia ejercerse según vía procesal ordinaria, culminando en un Tribunal Constitucional. Para ambos proponentes la competencia general de los jueces significaba la verdadera culminación del Estado de Derecho (ver C. SCHMITT, «Das Reichsgericht als Hüter der Verfassung" (1929), en Verfassungsrechtliche Abhandlungen, segunda edición, Berlin 1973, pág. 64, nota 5; pág. 65, nota 8).

182 La sentencia tiene una trascendencia especial, ya que suple un vacio - deliberado- de la Constitución por medio de una decisión judicial. Ello supone ya la completa disponibilidad de la Constitución por parte de los jueces. El sentido 
así la supremacia del poder Judicial. El imperio de la ley «deviene un imperio de la judicatura. La fundamentación teórica de la «judiciabilidad de la política», tan determinante para la evolución de la República de Weimar, no fue, como se ha repetido múltiples veces, el desenvolvimiento del Estado de Derecho del siglo xIX, sino su más completa perversión. El control judicial no se ejerce solamente sobre el Ejecutivo y la Administración, sino sobre el entretanto democrático legislador, de que, en un tiempo, se esperó la mas firme garantía jurídico-política de los derechos y libertades de la burguesia" ${ }^{183}$.

de la sentencia es perfectamente claro: "Dado que la Constitución no contiene precepto alguno que impida al juez decidir sobre la constitucionalidad de una ley federal, al no atribuir dicha facultad a ninguna otra instancia, ha de reconocerse como un derecho $\mathrm{y}$ un deber de los jueces el control de la constitucionalidad de las leyes federales" (cit. en C. ScHMITT, Das Reichsgericht..., cit., págs. 84-85).

${ }_{183}$ I. Maus, op. cit., pág. 41. 